\title{
How to change implicit drug use-related cognitions in prevention: a transdisciplinary integration of findings from experimental psychopathology, social cognition, memory, and experimental learning psychology
}

Citation for published version (APA):

Wiers, R. W., de Jong, P. J., Havermans, R., \& Jelicic, M. (2004). How to change implicit drug use-related cognitions in prevention: a transdisciplinary integration of findings from experimental psychopathology, social cognition, memory, and experimental learning psychology. Substance Use \& Misuse, 39(10-12), 1625-1684. https://doi.org/10.1081/JA-200033206

Document status and date:

Published: 01/01/2004

DOI:

10.1081/JA-200033206

Document Version:

Publisher's PDF, also known as Version of record

Document license:

Taverne

Please check the document version of this publication:

- A submitted manuscript is the version of the article upon submission and before peer-review. There can be important differences between the submitted version and the official published version of record. People interested in the research are advised to contact the author for the final version of the publication, or visit the DOI to the publisher's website.

- The final author version and the galley proof are versions of the publication after peer review.

- The final published version features the final layout of the paper including the volume, issue and page numbers.

Link to publication

\footnotetext{
General rights rights.

- You may freely distribute the URL identifying the publication in the public portal. please follow below link for the End User Agreement:

www.umlib.nl/taverne-license

Take down policy

If you believe that this document breaches copyright please contact us at:

repository@maastrichtuniversity.nl

providing details and we will investigate your claim.
}

Copyright and moral rights for the publications made accessible in the public portal are retained by the authors and/or other copyright owners and it is a condition of accessing publications that users recognise and abide by the legal requirements associated with these

- Users may download and print one copy of any publication from the public portal for the purpose of private study or research.

- You may not further distribute the material or use it for any profit-making activity or commercial gain

If the publication is distributed under the terms of Article 25fa of the Dutch Copyright Act, indicated by the "Taverne" license above,

Download date: 26 Apr. 2023 


\section{How to Change Implicit Drug Use-Related Cognitions in Prevention: A Transdisciplinary Integration of Findings from Experimental Psychopathology, Social Cognition, Memory, and Experimental Learning Psychology}

Reinout W. Wiers, Peter J. de Jong, Remco Havermans \& Marko Jelicic

To cite this article: Reinout W. Wiers, Peter J. de Jong, Remco Havermans \& Marko Jelicic (2004) How to Change Implicit Drug Use-Related Cognitions in Prevention: A Transdisciplinary Integration of Findings from Experimental Psychopathology, Social Cognition, Memory, and Experimental Learning Psychology, Substance Use \& Misuse, 39:10-12, 1625-1684, DOI: 10.1081/ JA-200033206

To link to this article: https://doi.org/10.1081/JA-200033206

\section{Published online: 16 Nov 2004.}

Submit your article to this journal

Џ Article views: 225

Q View related articles ๘

4 Citing articles: 2 View citing articles 준 


\title{
How to Change Implicit Drug Use-Related Cognitions in Prevention: A Transdisciplinary Integration of Findings from Experimental Psychopathology, Social Cognition, Memory, and Experimental Learning Psychology
}

Reinout W. Wiers, Ph.D., ${ }^{1, *}$ Peter J. de Jong, Ph.D., ${ }^{2}$ Remco Havermans, M.Sc., ${ }^{1}$ and Marko Jelicic, Ph.D. ${ }^{1}$

${ }^{1}$ Faculty of Psychology, Department of Experimental Psychology, Maastricht University, Maastricht, The Netherlands ${ }^{2}$ Department of Clinical and Developmental Psychology, Rijksuniversiteit Groningen, Groningen, The Netherlands

\begin{abstract}
A recent study from our lab found that an intervention aimed at changing alcohol-related cognitions in heavy drinkers resulted in significant changes in explicit cognitions, in the absence of changes in implicit cognitions. This raised the question how implicit alcoholand drug-related cognitions could successfully be changed. Here, the
\end{abstract}

*Correspondence: Reinout W. Wiers, Ph.D., Experimental Psychology, Uns 40, University of Maastricht, PO Box 616, 6200 MD, Maastricht, The Netherlands; Fax: +31-43-3884196; E-mail: R.Wiers@psychology.unimaas.nl.

1625

DOI: $10.1081 /$ LSUM-200033206

Copyright $\odot 2004$ by Marcel Dekker, Inc.
1082-6084 (Print); 1532-2491 (Online) www.dekker.com 
literature on changing implicit cognitions from four areas of research is reviewed: 1) memory research (resistance to change of implicit vs. explicit memories); 2) learning psychology (attempts to change learned associations); 3) experimental psychopathology (attempts to change an attentional bias); and 4) social cognition research (attempts to change implicit attitudes). Further, studies directly aimed at changing implicit drug-related cognitions are reviewed. From the integrative review, it is argued that it is important to consider the level of representation (i.e., specific vs. global) when comparing studies aimed at changing implicit cognitions: there is converging evidence that specific implicit cognitions and memories are resistant to change, whereas global implicit cognitions and memories appear to be more malleable. The results are integrated into an overall picture of what it takes to change implicit cognitions in general and what can be expected with respect to the effects of such a change on behavior, and how this could be used in alcohol-use and drug use-related preventive interventions.

Key Words: Alcohol; Attentional bias; Cognitive change; "Craving;" Drugs; Implicit cognition; Implicit Memory; Malleability; Prevention; Mental representation.

There is growing evidence that implicit and explicit cognitions differentially affect substance use and misuse, and preliminary evidence that interventions may have differential effects on implicit and explicit cognitions. This should have implications for future transdisciplinary research on the prevention of substance use and misuse. (This article)

"And when it came to the sixth or seventh (...), then I began to feel sick. I had like pains all over and felt I could sick up and at the same time not sick up, and I began to feel like in distress, $O$ my brothers, being fixed rigid too on this chair. When this bit of film was over I could slooshy the goloss of this Dr. Brodsky from over by the switchboard saying: "Reaction about twelve point five? Promising, promising." (Anthony Burgess, A Clockwork Orange, p. 82-83 (1962)).

\section{INTRODUCTION}

Written in the heyday of behaviorist psychology, Anthony Burgess' fictitious experiment (that describes the association of the main 
character's aggressive behavior with sickness) can be seen as a mad scientist's version of some of the recent attempts to try to influence implicit associations. Why would one want to change implicit associations, and what are they in the first place?

Recently, psychologists began to distinguish implicit and explicit cognitive processes; where implicit processes are automatic and largely outside conscious awareness, and explicit cognitive processes are more conscious and controlled processes. It was suggested that implicit and explicit processes are relatively independent (Greenwald and Banaji, 1995; Wilson 2000, 2002), related to different areas in the brain (e.g. Squire, 1992, see also Stacy et al., in this issue), and could have different developmental origins (Rudman, 2004). However, it should be noted that some researchers have argued that the implicit-explicit distinction should primarily be seen as denoting different assessment strategies as opposed to different cognitive processes (Fazio and Olson, 2003; Reingold and Toth, 1996). Most researchers nonetheless agree that implicit and explicit measures assess different aspects of cognitive processes (perhaps entirely different processes, perhaps different aspects of the same process). In this article potential implications of the implicit-explicit cognition distinction are explored with regard to implications for prevention research in the area of drug and alcohol "abuse." If implicit and explicit cognitions exert differential influences on behavior, as many studies from different areas suggest, what can be concluded with respect to drug use and misuse prevention? Most current efforts are aimed at changing explicit cognitions, and perhaps future prevention can be improved by supplementing or even replacing these methods with new methods aimed at changing implicit cognitions.

This article reviews four rather separate research areas in which implicit cognition has been studied, with more or less attention to change processes:

- Implicit memory.

- Learning psychology.

- Experimental psychopathology.

- Social cognition research.

${ }^{1}$ The journal's style utilizes the category substance abuse as a diagnostic category. Substances are used or misused; living organisms are and can be abused. Editor's note. 
Although all these areas could be viewed as subdisciplines of experimental psychology, each have their own dimensions, operational conditions, traditions, and research questions and have rarely been integrated (we are not aware of another paper integrating these areas). The reason why we chose these four areas is that recent work on implicit cognition is rooted in implicit memory research, that work on changing learned associations is rooted in learning psychology, and that recent efforts to change implicit cognitive processes have been undertaken in experimental psychopathology and in social cognition research. In addition, some work has been implemented that directly relates to substance use and misuse and this will also be reviewed. Of course, our choice of these research domains does not imply that no work in other areas of research is being done that could be relevant to the central question of this article. All areas reviewed here have provided valuable insights into the nature of implicit cognitions, their role in predicting behavior, and have sometimes provided clues to answer the main question of this article: how to change implicit (drug-related) cognitions. We will argue that a rather coherent view emerges from the integration of these relatively independent areas of research, an integration that we hope may provide new clues for needed and effective applications in prevention research. Further, the reviews of the different domains are meant to indicate new, potentially interesting lines of research that might be relevant for the question of how to change implicit drug-related cognitions, rather than being exhaustive reviews. A brief impression of the potential relevance of studying implicit cognition in research on substance use and misuse is presented before reviewing these domains.

\section{IMPLICIT AND EXPLICIT COGNITIONS IN PSYCHOLOGY AND SUBSTANCE (MIS)USE}

Over the past 10 years there has been an increased focus on implicit assessment of drug-related cognitive processes (including alcohol and nicotine). By implicit assessment we mean more indirect measures that contrast with explicit measures, such as questions in a questionnaire that require introspection about one's own mental processes (Fazio and Olson, 2003; Greenwald and Banaji, 1995). Indirect measures have been introduced for at least two nonexclusive reasons:

- First, people may sometimes try to hide their motives or try to answer in accordance with how they believe the researcher wants them to respond (social desirability). 
- Second, people may not be aware of (some of the) motives that drive their behavior (Nisbett and Wilson, 1977).

A strong version of the second proposition would be that implicit and explicit cognitive processes operate rather independently and are related to different underlying neural processes.

After acknowledging the different views on implicit and explicit cognition (different tool to assess one underlying true cognition vs. tapping into different processes), we now further define what we mean by drugrelated cognitive processes. First, it is important to distinguish between individual differences in cognitive processing that are specifically related to drug(s) with respect to contents (e.g. a problem drinker's increased attention for alcohol-related words) and more general differences in psychological functioning that are not specifically related to addiction (e.g., impulsivity or executive functions). ${ }^{2}$ The psychological processes discussed in the remainder of this paper are (drug-)content-specific. Although not the focus of this chapter, it should be noted that more general individual differences in personality might influence the development of implicit drugrelated cognitions, e.g., an impulsive person might more easily develop drug-arousal associations and a more anxious person may more easily develop associations between a negative mood and a substance of use or abuse (Erblich et al., 2001; see also Stacy et al., in this issue). Drug-contentspecific implicit cognitions are studied in different paradigms and are rooted in different branches of experimental psychology.

As indicated, the implicit-explicit distinction is rooted in memory research. This will be briefly reviewed first (by Marko Jelicic), followed by a short discussion of approaches that aim to measure specific drugrelated memory biases. The work of Stacy and colleagues is the bestknown example in reseach on substance use and misuse, and is already reviewed in another paper in this issue (Stacy et al., in this issue). Stacy

\footnotetext{
${ }^{2}$ With respect to the second type of individual differences, there is accumulating evidence that individual differences in personality (e.g., "behavioral undercontrol (Sher, 1991) or "a mild deficit in executive functioning" (Pihl and Bruce, 1995; see also Stacy et al., in this issue; Wiers et al., 1998) may place one at increased risk for the development of addiction. This increased susceptibility is not uniquely related to addiction: it can be viewed as a more general tendency to take risks that may have a variety of behavioral outcomes, ranging from an increased risk for accidents to an increased chance of having children at a young age, and can be viewed as an adaptive evolutionary strategy ("live fast, die young") (Gerald and Higley, 2002).
} 
and colleagues used a variety of tests in which first associations are spontaneously generated to ambiguous stimuli (e.g., draft), to ambivalent situational cues (e.g., Friday night), and to ambivalent outcome cues (e.g., feel relaxed), demonstrating that the number of drug-related associations is related to prospective drug use, even after controlling for previous drug use and explicit cognitions. Another approach involves drug-related incidental recall (Franken et al., 2003). Most of these tasks are paper and pencil tests, which has both advantages and disadvantages: it makes them easy to use in prevention and it focuses on personal associations, but these tests could also be more vulnerable to censoring control processes ("No, let's not write down that association....").

A second branch of experimental psychology that is relevant for the central issue of this article concerns learning psychology, rooted in the behaviorist tradition (reviewed by Remco Havermans). There is still considerable debate as to what extent associative learning can be implicit (Lovibond and Shanks, 2002). As will become evident from the review, recent research in this tradition suggests that it may be impossible to unlearn a once-learned association. This finding is important for attempts to change implicit drug-related associations (e.g., cue-exposure), and may have implications for prevention (general discussion).

The third branch of experimental psychological research relevant here concerns experimental psychopathology research (reviewed by Peter de Jong). In this area, most research efforts have focused on demonstrating an attentional bias for problem-relevant stimuli, mostly related to anxiety (e.g., the attention of spider phobics appears to be automatically drawn to spider-related stimuli). A large number of studies have demonstrated the existence of a psychopathology-related attentional bias. Some recent studies have gone further than merely demonstrating the existence of an attentional bias and have started to study how an attentional bias can be changed, either through conventional techniques (e.g., cognitive behavioral therapy), or in some recent instances, through experimental techniques that directly try to change the attentional bias. In research of substance use and abuse, there is also a considerable literature demonstrating the existence of a drugrelated attentional bias, and some preliminary research assessing effects of interventions on these biases. We are not aware of research yet that also tried to directly change drug-related attentional biases through experimental techniques.

Finally, a branch of experimental psychological research in which a great deal of implicit cognition research has been done in recent years concerns social cognition research (reviewed by Reinout Wiers). In this area, a variety of measures have been developed to assess implicit 
attitudes (in the Appendix a brief description is given of each of the tests discussed). Among the most employed measures are the Implicit Association Test (IAT) (Greenwald et al., 1998) and recent varieties such as the Extrinsic Affective Simon Task (EAST) (De Houwer, 2003), and Affective Priming (Fazio et al., 1986 see Fazio, 2001 for a review). These tests are all speeded reaction time (RT-)tests, but in this area paper and pencil tests are used also (Greenwald and Banaji, 1995). As yet, only a small number of studies applied these and similar techniques to substance use and misuse, (smoking: Swanson et al., 2001; alcohol: Jajodia and Earleywine, 2003; Palfai and Ostafin, 2003, Wiers et al., 2002; see Wiers and De Jong in press for a review) and little is known about how to change implicit drug-related associations (the few studies that directly addressed this issue are reviewed). However, in social cognition research, some recent studies were conducted that investigated ways to change implicit associations (usually implicit negative stereotypical attitudes), which will be reviewed below. Moreover, some recent work in this area has focused on the momentary malleability of implicit cognitions (Blair, 2000; Mitchell et al., 2003), which may alter the way implicit cognitions are viewed (discussed in the integrative section).

The remainder of this article reviews these four areas of experimental psychology research (experimental psychological approaches to memory, learning, psychopathology, and social cognition) followed by a short review of related studies in research on substance use and misuse. The final section integrates the findings from the different areas of research and then discusses general issues pertaining to the question of how to change implicit cognitions, before turning to potential applications in drug-use and misuse-prevention research.

\section{CAN IMPLICIT MEMORIES BE CHANGED?}

Memory can be expressed in either an explicit or implicit way (Roediger, 2003; Schacter, 2001). Tests of recall and recognition require conscious recollection of a previous learning episode and have been labeled explicit memory tasks. In a typical explicit memory experiment, participants are presented with information (words or pictures) to remember, and after a delay, they are asked to think back to the study phase in order to recall or recognize the study material. (Note that most traditional tests of knowledge acquired through prevention are similar to these explicit recognition tasks.) Implicit memory tasks, on the other hand, do not demand conscious recollection; implicit memory is revealed by a change or facilitation in test performance without participants 
realizing that a memory test is taking place. Implicit memory is often measured with repetition priming tasks. These priming tests can be classified as either perceptual or conceptual (Roediger, 1990). Perceptual implicit memory tests challenge the perceptual system by presenting the test cue either briefly or in a fragmented form. An example of a perceptual priming task is the word-fragment completion test (Tulving et al., 1982). In the study phase, participants are presented with words (e.g., ELEPHANT). After a delay varying from seconds to weeks, they are asked to complete fragments of words (e.g., _L_PH_T). In this test, priming is evidenced if fragments corresponding to study words are more often completed than fragments from words that were not presented during the study phase. In conceptual implicit tests the test cues are conceptually, rather than physically, similar to the target items. An example of a conceptual priming task is the category production test (Graf et al., 1985). In the study phase, participants are presented with less common exemplars from different semantic categories (e.g., CANTALOUPE from the category FRUIT). Some time later they are asked to generate random exemplars from a number of categories. In this test, there is evidence for priming if the critical exemplars are more often generated than can be expected from baseline performance.

Ten years ago, it was believed that many variables or conditions that have large effects on performance in explicit memory tasks hardly influence implicit memory performance (e.g., Parkin, 1993). More recently, however, it has become increasingly clear that variables affecting explicit memory may (to some extent) also influence conceptual implicit memory. Explicit memory performance is dependent on the level of processing during encoding, i.e., participants are better able to recall or recognize the study material after semantic processing than after shallow processing. Depth of processing has a very small effect on priming in perceptual implicit memory tasks (Graf and Mandler, 1984; Jacoby and Dallas, 1981), but does affect conceptual implicit memory performance to some degree (Mulligan et al., 1999). In a similar vein, divided attention during study strongly reduces performance on explicit memory, but leaves perceptual implicit memory performance intact (Parkin and Russo, 1990; Wolters and Prinsen, 1997). It was recently demonstrated that a manipulation of attention has some influence on priming in conceptual tasks (Mulligan and Stone, 1999). Benzodiazepines are used in clinical psychiatry to treat patients with anxiety disorders. These drugs also cause temporary amnesia (Hirshman et al., 2001). In a recent study, explicit and implicit memory performance were tested after the administration of a benzodiazepine (midazolam). While leaving perceptual implicit memory intact, the medication did affect both explicit and 
conceptual implicit memory (Hirshman et al., 2001). Another example comes from studies of elderly people, who typically show impairments in explicit memory (e.g., Jelicic et al., 1996). In this study, elderly people were outperformed by young participants on explicit memory and conceptual implicit memory tasks, but no age-related decrement in perceptual implicit memory tests were found. There is even literature to suggest that patients with Alzheimer's disease have preserved perceptual implicit memory capabilities and impaired conceptual capabilities (Meiran and Jelicic, 1995).

In contrast with previous thoughts on implicit memory (Parkin, 1993), recent research shows that, while perceptual priming is quite a robust phenomenon, conceptual implicit memory is more amenable to change. Neurological factors might explain this discrepancy. For example, Gabrieli argued that the two types of implicit memory are mediated by different brain areas (Gabrieli, 1999). Whereas perceptual priming would be subserved by the primary sensory cortices in the brain, conceptual priming would be mediated by the association cortices. Since there is much more plasticity in the association cortex than in the sensory cortex, conceptual implicit memory would be more malleable than perceptual implicit memory.

\section{How to Change Drug-Related Implicit Memories}

A number of studies have applied techniques from memory research to the study of substance use and misuse (Stacy, 1997; in this issue). However, very few studies have investigated the effects of an intervention on drug-related memories. The only two studies we could identify were two from Krank and colleagues. In the first, (Krank and Swift, 1994) the investigators applied Jacoby's false-fame paradigm (Jacoby and Kelley, 1987; Jacoby et al., 1989) to an alcohol-prevention context. Participants in this study were presented with a number of facts and myths about alcohol (e.g., "it is a fact that alcohol makes you sleepy"; "it is a myth that alcohol makes you sexy"). Directly after reading the materials, participants successfully distinguished between facts and myths. However, $24 \mathrm{~h}$ later, facts and myths were no longer distinguishable: the statements that had been labeled as being myths were rated as high on truthfulness as the statements that had been presented as facts. This preliminary finding clearly has implications for prevention programs. It is possible that program information could have a reverse, negative effect or effects opposite to those intended by the researchers if memory processes are not considered (e.g., increases in memory for positive 
consequences instead of negative consequences). More generally, in druguse prevention, one has to beware of unintended effects of the intervention (Dishion et al., 1999). For example, it was found that the mere assessment of a puppet-aided instrument of alcohol expectancies in children could result in unintended modifications of these alcohol-related expectancies (they became more positive) (Wiers et al., 2000; see also Schwartz, 1999). In a recent study (Krank and Kreklewetz, 2003), the effects of alcohol advertising on implicit and explicit memory in young adolescents was investigated. It was found that exposure to five alcohol commercials (mixed with other commercials) increased alcohol-related responses on implicit but not on explicit memory tests, and this was found only in drinkers, and only directly after exposure (not $24 \mathrm{~h}$ later). This interesting finding suggests that personal experience may be a crucial factor in the development of implicit alcohol-related cognitions (for a similar argument regarding explicit expectancies, see Wiers et al., 1998). To what extent advertising influences implicit (and explicit) alcohol-related memories over a longer time interval and how this ultimately influences behavior constitutes an important area for future research.

\section{UNLEARNING ASSOCIATIONS?: FINDINGS FROM LEARNING PSYCHOLOGY}

Learning theory covers over a century of research, and as of today, remains a dynamic research area. It has offered valuable insights into both animal and human behavior and cognition. Although most readers will have some idea of classical (Pavlovian) conditioning, recent insights from learning theory are less well known (Rescorla, 1988). Contemporary learning theory and research focuses primarily on Pavlovian stimulusstimulus learning processes. As opposed to stimulus-response learning, experimenters can exert direct control over the learning of stimulusstimulus associations (see Pearce and Bouton, 2001). In Pavlovian learning, repeated pairing of a neutral, conditioned stimulus (e.g., a tone) with a biologically relevant unconditioned stimulus (e.g., food), will lead to the formation of an association between the conditioned stimulus and the unconditioned stimulus. Such an association gives rise to conditioned responding to the conditioned stimulus reflecting anticipation of the biologically relevant stimulus (e.g., the famous Pavlovian salivation response to the tone in anticipation of food).

Much research has been devoted to extinguishing conditioned responding. Such extinction can be accomplished by repeated 
nonreinforced exposure to the conditioned stimulus. In general, extinction of conditioned responding was thought to occur due to the gradual elimination or erasure of the initially learned association. In other words, extinction has been said to reflect the unlearning of an association (Rescorla, 2001). Importantly, it is now clear that this assumption was false. Several phenomena demonstrate that an extinguished response can return, implying that extinction does not entail the erasure of an initially learned association.

One such phenomenon concerns reinstatement. In animals, single reexposure to the unconditioned stimulus after an extinction procedure leads to the immediate reinstatement of conditioned responding, hence not reconditioning (Rescorla and Heth, 1975). Another related phenomenon concerns renewal. When an animal is exposed to the conditioned stimulus in a context that differs from the extinction context, conditioned responding is renewed (Bouton, 1993). Bouton (1993; García-Gutiérrez; and Rosas, 2003) argues that due to extinction, the conditioned stimulus acquires an ambiguous meaning, predicting both the presentation of the outcome and the absence of the outcome. Animals disambiguate the meaning of the conditioned stimulus by paying close attention to the context in which the extinction treatment is carried out. Within the extinction context, the inhibitory meaning of the conditioned stimulus is retrieved from memory, whereas outside the extinction treatment context the conditioned stimulus will still be able to elicit strong responding. Such context specificity of extinguished conditioned performance also appears to occur in humans (García-Gutiérrez and Rosas, 2003).

Thus, extinction does not appear to be able to alter or modify an initially learned association. The same conclusion can be drawn for a counter-conditioning procedure. Counterconditioning refers to the treatment in which, after the learning of an initial association, the conditioned stimulus is repeatedly paired with another unconditioned stimulus (e.g. an electric shock instead of food). This results in the learning of a conditioned response (e.g., fear responding characterized by avoidance) that counters the initially learned response (e.g., appetitive responding characterized by approach). Recently, Nelson (2002) demonstrated that such a counterconditioned response is also highly context specific. $\mathrm{He}$ argued that a second learned association, whether inhibitory or excitatory, would come under the modulator control of the context in which this second association is learned.

It could be argued that next to Pavlovian conditioning, drug use entails evaluative conditioning. Evaluative conditioning refers to the learning of an association between an initially neutral stimulus and an affective stimulus (positive, or negative), leading to the transfer of 
affective valence from the affective stimulus to the neutral stimulus. For example, pairing a neutral picture with a liked picture will lead to a positive shift in liking for the initially neutral picture (De Houwer et al., 2001). Evaluative conditioning is a very robust and general phenomenon. In contrast with Pavlovian learning though, evaluative conditioning typically does not require specific contingencies between stimuli. However, as in Pavlovian conditioning, evaluative associations are highly resistant to extinction procedures. It has been found that acquired liking can be attenuated through counterconditioning, now pairing the stimulus with an aversive stimulus (see De Houwer et al., 2001). However, since counterconditioning in Pavlovian learning does not appear to alter the initially learned association (Nelson, 2002), it may be questioned whether counterconditioning in evaluative conditioning truly reflects a change in the originally learned association.

In summary, it appears that an initially learned association cannot be modified or erased, but that the learning of a second association can interfere with the retrieval of the first learned meaning of the conditioned stimulus, which may be useful in drug-use prevention research.

\section{How to Change Conditioned Drug-Related Associations}

Pavlovian stimulus-stimulus learning has often been proposed as one of the primary mechanisms underlying the development, maintenance, and relapse of addictive behavior (e.g., Robinson and Berridge, 2003). Note that lapses and relapse may be a necessary dimension of a change process. In general, according to the present learning view, every instance of drinking constitutes a learning trial in which alcohol-related stimuli (e.g., the sight, smell, and taste of one's favorite drink) become associated with an alcohol effect (e.g., a psychomotor stimulant effect). Of course, instrumental conditioning principles may play an important role in the development of substance misuse as well, in the sense that drug-seeking behavior is reinforced by the hedonic effects of the drug. This instrumental drug-seeking behavior, however, can be modified by a Pavlovian-conditioned drug stimulus (Glautier and Remington, 1995). For example, alcohol cues are considered to function as conditioned alcohol stimuli and as such, exposure to these alcohol-related cues comes to elicit conditioned alcohol responding, or alcohol cue reactivity. Such cue reactivity comprises subjective (e.g., increase in urge to drink), psychophysiological (e.g., change in heart rate), and behavioral responding (e.g., alcohol-seeking behavior) (Glautier and Remington, 1995). 
If one assumes that implicit alcohol associations play a key role in alcohol drinking behavior, then successfully preventing alcohol use and/or misuse lies in modifying these alcohol associations. Since these associations can be considered to be the result of associative learning processes, it seemed logical to try to use an extinction procedure to modify these associations. In analogy with the extinction of conditioned responding in animals, alcohol cue reactivity can be extinguished by repeatedly exposing an alcohol-dependent patient to alcohol cues while preventing him (or her) from drinking (Rohsenow et al., 1995). One recent study (Palfai and Ostafin, 2003) investigated the association between implicit alcohol associations and urge to drink in a single cue exposure session (not a cue exposure treatment) and found that implicit alcohol-approach associations were associated with urge to drink after cue exposure, but not with urge to drink at baseline (in line with incentive motivational theories of addiction) (Robinson and Berridge, 2003). This may indicate that implicit approach associations measured in a dry situation, may reflect the automatic approach associations a person holds when confronted with relevant drug stimuli.

Although an exposure treatment seems to be promising, the efficacy of cue exposure as a method to modify implicit alcohol-related associations may be questioned. As described previously, extinction typically does not entail the unlearning of an initially learned association. Indeed, results from several recent animal studies have shown that conditioned alcohol tolerance and conditioned drug-seeking behavior in rats can be renewed after an extinction procedure, due to a context switch (Brooks et al., 2001; Crombag and Shaham, 2002). Although one should be careful of drawing conclusions about behavior from other species to humans, there is some indication that this renewal of conditioned alcohol or drug responding also occurs in humans. In reviewing the literature on the efficacy of cue exposure treatment in preventing the relapse of addictive behavior, Havermans and Jansen (2003) noted that cue exposure treatment can successfully extinguish cue reactivity in drug dependent patients, but outside the treatment setting cue reactivity is still observed in these patients. In line with this idea, it has been argued that the renewal effect provides an adequate explanation for the relative inefficacy of cue exposure treatment in preventing relapse of addictive behavior (Conklin and Tiffany, 2002). Indeed, renewed alcohol cue reactivity has been experimentally induced in heavy drinkers (Collins and Brandon, 2002). They exposed these drinkers to alcohol related cues, which led to the gradual extinction of subjective (i.e., craving) and psychophysiological responding (i.e., salivation) to the alcohol cues. 
However, when these participants were exposed to the alcohol cues in another environmental context, alcohol cue reactivity was renewed.

These findings suggest that one cannot simply modify alcohol associations. One thing to aim for is teaching new inhibitory associations that may interfere with the retrieval of the initially learned implicit alcohol-related associations. Since this second learned association will not easily generalize to contexts other than the treatment setting, it can be concluded that an exposure treatment alone is not sufficient. Some additional method has to be devised promoting the generalization of the newly learned association (see Havermans and Jansen, 2003 for a detailed discussion of such methods). It should be emphasized that aspects of this review are somewhat speculative and that future research is required to determine whether an extinction-based treatment such as cue exposure with response prevention is able to affect implicit alcoholrelated associations, and if so, whether such an effect is context specific. Finally, with respect to prevention, it is likely that new substance associations develop when an adolescent begins to use (the individual may already have associations from observational learning and advertising, either pro- or contra use). Secondary prevention, aimed at individuals who have begun using the substances, should acknowledge this. It may be concluded from learning psychology that the context of substance use is important, and context specificity of associations should be addressed in order to prevent the risk of classroom wisdom vs. street stupidity (see also Stacy et al., in this issue).

\section{HOW TO CHANGE A PSYCHOPATHOLOGY-RELATED ATTENTIONAL BIAS}

An important impetus behind the increasing research studying implicit cognition in the context of psychopathology was the rise of cognitive models implying that mood and anxiety disorders critically depend on the existence of maladaptive cognitive structures in memory (Beck et al., 1985). These so-called schemata are assumed to automatically influence all stages of individuals' information processing. Since relevant cognitions may not be accessible through introspection, empirical research to test the validity of this type of model predominantly relies on indirect (implicit) performance-based measures of cognitive processes that are assumed to be functionally related to the underlying maladaptive schemata (e.g., Mansell, 2000).

In line with the idea that dysfunctional cognitive representations might play a role in psychopathological problems such as anxiety 
disorders, there is ample evidence indicating that anxiety patients prioritize processing of potentially threatening information. For example, using an emotional Stroop paradigm (see Appendix) anxiety patients are typically found to be slower in naming the color of threatening words than of neutral control words, suggesting that their attention is attracted and/or held by the meaning of threatening material thereby interfering with their performance in colornaming (see Williams et al., 1996). Similarly, using a dot probe detection task (see Appendix), patients typically detect probes fastest when they appear in the vicinity of threat words (MacLeod et al., 1986). It should be noted that currently there is debate about the question which attentional subprocess is responsible for the disorder specific attentional biases; whether attention is more quickly drawn to the disorder-relevant stimuli (the attentional shift component) or whether it is due to a greater difficulty to disengage attention from disorder-relevant stimuli (for preliminary evidence favoring the disengagement component in anxiety (Fox et al., 2001)). In support of the idea that particular maladaptive schemata characterize particular disorders, this sensitivity for threatening cues has been found to be specific for the patients' typical concerns. Accordingly, panic patients typically display an attentional bias for words such as heart attack and suffocation, whereas social phobic individuals typically show an attentional bias for stimuli related to social rejection and negative evaluation (e.g., Ehlers et al., 1988; Hope et al., 1990).

More recent work indicates that this type of attentional bias can even be found when words are presented too briefly to allow patients to become aware of the content of the words (subliminal presentation) e.g., Macleod and Hagen (1992). Hence, this type of processing bias seems highly automatic and not dependent on conscious processing. Whereas the supraliminal emotional Stroop effects (using longer presentation times) are usually restricted to individuals displaying clinical symptoms, interference effects under subliminal conditions can also be found in the preclinical range (e.g., Macleod and Hagen, 1992). This suggests that the ability to control (or inhibit) the automatic processing of emotionally meaningful information is an important factor differentiating preclinical from clinical anxiety (cf., De Jong et al., 2003).

\section{Attentional Bias and Treatment}

To the extent that anxiety patients' tendency to favor processing threat-related information over neutral or positive information serves to maintain the disorder, attentional bias should be attenuated (or 
eliminated) following successful treatment. Perhaps surprisingly, thus far only a few studies have examined the influence of treatment on attentional bias. Yet, a consistent (and encouraging) finding of these studies is that this type of bias seems amenable to treatment. It has, for example, been shown in the context of spider phobia, that a single session of $2.5 \mathrm{~h}$ exposure in vivo was sufficient to significantly reduce phobic participants' attentional bias for spider-related words (Lavy et al., 1993). In line with the alleged reciprocal relationship between attentional bias and the severity of anxiety complaints, there was a significant association between the decrease of Stroop interference and the reduction of phobic avoidance behavior (hence patients showed less fear when confronted with spiders). Similar results were found when pictorial rather than verbal stimuli were used (Lavy and Van den Hout, 1993).

Testing social-phobic individuals before and after cognitive behavioral therapy, phenelzine, or placebo, it has been shown that treatment responders displayed a significant reduction in latencies to name social threat words (Mattia et al., 1993). Finally, it has been shown that a sevensession anxiety management (group) training was not only successful in dramatically reducing General Anxiety Disorder (GAD) patients' complaints, but also in reducing their attentional bias to threat words (Mathews et al., 1995).

Several authors expressed doubt as to whether preconscious attentional biases would similarly be amenable to treatment (e.g., McNally, 1995). However, two recent studies testing this issue clearly showed that cognitive behavioral therapy could successfully reduce both conscious and preconscious attentional bias. First, Mogg and colleagues showed that anxiety management training served to reduce the elevated color-naming interference shown on subliminally presented (i.e., masked) threat words in GAD patients $(n=11)$, although this change in cognitive bias did not appear to be maintained at 18 months follow-up (Mogg et al., 1995). Meanwhile, underlining its potential importance in maintaining the disorder, greater reduction in the interference effect of masked anxiety words was associated with a greater reduction of anxious thoughts. This association was evident both from baseline to immediately after treatment and from baseline to 18 months follow-up. Second, it has been shown that a single session exposure in vivo significantly reduces preconscious attentional bias in spider phobics $(n=21)$ (Van den Hout et al., 1997). Together these findings suggest that a preconscious attentional bias is not an immutable feature of anxiety prone individuals but is susceptible to the effects of psychological treatment.

From both a theoretical and a practical perspective it would be important to see whether a residual bias is predictive of the return of 
complaints. Unfortunately, thus far none of the studies on attentional bias tested the predictive power of residual attentional bias for relapse. Meanwhile, a recent study measuring implicit spider-related associations rather than attentional bias did address this issue (Teachman and Woody, 2003). Although this first exploration of the malleability of implicit (spider fear) associations over the course of treatment convincingly showed that an exposure treatment can weaken implicit fear associations, unfortunately there was not sufficient variation of treatment success at follow-up to optimally test the alleged additional predictive power of implicit measures for relapse. Clearly, further treatment outcome studies are needed to explore this important issue.

Taken together, there is evidence that anxiety patients are characterized by conscious and preconscious processing biases, although it is less clear which attentional subprocesses are responsible for this phenomenon. In addition, studies examining the effects of treatment on attentional bias indicate that these threat-specific biases may be attenuated or even eliminated as a function of treatment. Moreover, there is evidence that decreases in attentional biases are associated with improvement of the patients' complaints. Although this pattern of findings is in line with the idea that attentional bias plays a critical role in the maintenance of psychopathological complaints, it is also consistent with the interpretation that attentional bias is a consequence rather than a cause of pathological anxiety. Indeed, there is empirical evidence that attentional bias can be induced in nonanxious individuals by means of aversive classical conditioning (Merckelbach et al., 1990). To more directly examine this important issue of causality, MacLeod and colleagues (MacLeod et al., 2002) experimentally induced an attentional bias using a modified dot-probe task and tested the impact of this manipulation on subsequent emotional vulnerability. They tested students with average anxiety levels, and during a large number of training trials (576), half of the participants consistently moved toward negative stimuli (experimental condition: attentional bias induction) and half of the participants consistently moved away from the negative stimuli (control condition) in the modified dot-probe task. This manipulation successfully induced an attentional bias: in the experimental condition, participants were faster on (new) negative words than on (new) neutral words on test trials, and in the control condition the opposite was found. The training had no effect on mood during the training. However, after a stress task, the experimental group reported higher levels of anxiety than did the control group (and again in a replication study in the same paper). These results clearly supported the idea that attentional bias can causally mediate emotional vulnerability, 
lending substance to the previously speculative suggestions concerning the proposed causal role of attentional bias (see also Matthews and MacLeod, 2002). Meanwhile, the finding that a bias induction in nonanxious individuals can lower the threshold for evoking negative emotional reactions, also points to an exciting therapeutic application. That is, it suggests that a similar modified cognitive-experimental dotprobe task may also be used to reduce an already existent bias in anxiety patients, thereby reducing these patients' anxiety complaints. In fact, suggestive evidence was found in the (nonclinically anxious) controlgroup: those participants who responded to the attentional training manipulation with the most pronounced attentional avoidance of negative stimuli, showed the strongest attenuation of the negative emotional impact of the subsequent stress procedure (MacLeod et al., 2002). It should be noted that this type of study may raise some ethical issues: if indeed an attentional bias plays a causal role in the development of anxiety disorders, one should be very careful in inducing this (remembering Watson's little Albert). ${ }^{3}$ The authors selected participants from the middle range on trait and state anxiety scores (excluding participants with high scores for whom the allocation to the attentional bias induction condition could be problematic) and note that further studies on the effects of prolonged attentional training should focus on reducing, rather than increasing, attentional orientation toward negative information, for ethical reasons.

Subsequent research in a nonreferred sample of chronic worriers ( $40 \%$ met criteria for generalized anxiety disorder; GAD), lends more direct support to the idea that attentional retraining (AR) might be useful as a therapeutic tool (Vacey et al., 2002). At 5-day intervals, participants were exposed to five sessions of $30 \mathrm{~min}$ of AR using a modified dot-probe task. In the treatment condition each session consisted of 216 trials in which probes followed neutral words on 204 trials. The placebo condition was identical to AR with the exception that probes followed neutral words on $50 \%$ of the trials and threat words on the remainder. The placebo condition did not affect individuals' bias for threat nor their scores on the anxiety pathology questionnaires. Meanwhile, the

\footnotetext{
${ }^{3}$ Watson and Rayner taught a young boy named Albert to become afraid of a gentle white rat. At the beginning of the study, Albert was unafraid of the white rat and played freely with the animal. While he was playing with the rat, the experimenters frightened the child by making a loud noise behind him. Albert was startled and began to cry. Thereafter, he avoided the rat and would cry whenever it was brought close to him.
} 
treatment condition not only resulted in an attenuated threat bias, it also led to a considerable reduction of individuals' symptom scores. Adding to its clinical significance, these treatment effects compared favorably with the average effect for cognitive behavioral therapy for GAD in past published studies. Another recent study (Dandeneau and Baldwin, 2004) found that AR had a positive effect on implicit self esteem in individuals with low self esteem. Clearly, AR has promise as a new treatment tool in anxiety-related psychopathology.

\section{How to Change a Drug-Related Attentional Bias}

As indicated earlier, there is now quite some evidence for the existence of a drug-related attentional bias in relation to substance use and misuse (for a recent review, see Franken, 2003). As to the distinction between attentional subprocesses, there is preliminary evidence both for faster detection of drug-related stimuli and for longer processing of drugrelated stimuli (in smoking, Mogg et al., 2003). As yet, relatively few studies have aimed to modify an alcohol- or drug-related attentional bias.

Cox and colleagues (2002) tested 23 alcohol-dependent patients on admission to inpatient treatment and immediately before discharge, four weeks later (the 14 patients who were still in treatment). Results were compared with non-misusers (as is often the case in these studies: socially drinking staff from the same unit, $n=20$ ). An attentional bias for alcohol-related stimuli was measured with a modified emotional Stroop test (see Appendix), in which reaction times on the color-naming task were compared for alcohol-related words vs. neutral words, as well as on a third dimension: personal concerns in other areas of life (e.g., job, housing, relationship, health). Personalized stimuli were used both for the alcohol words and for the concerns. Interference scores at time 1 on personal concerns were higher for patients who left treatment prematurely than for the other two groups. Of those patients who finished treatment $(n=14)$, five had remained abstinent during the three months after discharge from the clinic, while nine had relapsed or had not maintained contact. The three remaining groups (controls, successful patients, and unsuccessful patients) did not significantly differ in their attentional bias for alcohol on admission to inpatient treatment, but the unsuccessful alcoholics showed a stronger attentional bias for alcohol words at time 2, prior to discharge. These findings suggest two things: first, that when patients are strongly concerned with other problems than their alcohol problem alone, they are likely to drop out prematurely, which is in accordance with the cognitive motivational model of 
Cox and Klinger (1988). Second, alcoholic patients who develop a stronger attentional bias during treatment are more likely to relapse than alcoholics who have a stable attentional bias during treatment. Hence, the question may not (only) be how to moderate a drug-related attentional bias in treatment, but rather how to prevent a drug-related attentional bias from becoming stronger during treatment (or during abstinence). In other words, how can one prevent patients from becoming increasingly concerned with alcohol during treatment? (But of course one should be aware that this was a small study and that different treatments may have different effects; there are ample research opportunities in this largely unexplored area).

Two recent cross-sectional experiments investigating attentional bias in smoking (Bradley et al., 2003) demonstrated that the attentional bias of smokers did not differ from that of nonsmokers, but that within the group of smokers, individuals with a history of unsuccessful quit attempts did show a greater attentional bias than nonsmokers and smokers who made few quit attempts. From both studies, it can be tentatively concluded that a drug-related attentional bias is a negative predictor of abstinence. The question remains how an attentional bias could be successfully modified, and if possible, to what extent that would predict treatment outcome. Waters and colleagues (2003) tested 158 smokers who wanted to quit smoking in a structured smoking-cessation program including a high-dose nicotine patch and a placebo-patch condition. Attentional bias was assessed with two measures administered at different times in the program: a dot-probe test (see Appendix) was administered on day 3 (in the preparation phase while they were still smoking) and an emotional (Smoking) Stroop test (see Appendix) was administered during the evening of day 17 of the program, some $12 \mathrm{~h}$ after the beginning of the actual quit attempt. Findings differed considerably for the two measures. An attentional bias was found in the dot-probe task, but this measure did not predict outcome. Further, the associations with craving were complex: no correlation with pretest craving was found, but an exploratory analysis showed a positive correlation between pretest craving and the attentional bias during the first half of the Stroop test. The emotional Stroop task was also analyzed for the first subblock separately (acute Stroop), in addition to the overall interference measure. The acute Stroop interference significantly predicted one-week abstinence (with marginally significant prediction for the full-test Stroop), and only the acute Stroop interference predicted time to first lapse. No effect of the nicotine patch condition on the Stroop interference scores was found (there was a main effect of condition, indicating that participants in the nicotine patch condition 
responded faster irrespective of word contents), nor an association with craving. When clinical outcomes were analyzed for the two conditions separately, it was found that the Stroop interference scores were predictive of treatment outcome in the placebo but not in the nicotine patch condition. One may speculate that the nicotine patch may exert its effect by attenuating a smoking-related attentional bias.

Franken et al. (2004) tested whether an attentional bias for heroin cues could be attenuated by giving detoxified heroin addicts a dopamine antagonist (haloperidol) and compared their attentional bias with the attentional bias after placebo in a double-blind randomized crossover design. A dopamine antagonist was used because, according to incentive sensitization theory, (Franken et al., 2002; Robinson and Berridge, 1993, 2001) dopamine is believed to underlie the increased attention for drugrelated stimuli in people misusing drugs. Hence, the hypothesis of the study was that the attentional bias for heroin words would decrease in the haloperidol condition, as compared with the placebo condition. Indeed, participants were faster in the emotional Stroop task in the haloperidol condition than in the placebo condition, however, this was found both for heroin words and for neutral words (the latter was unexpected, and could be due to carry-over effects from heroine to neutral words). The difference in reaction times between the two conditions was only significant for the heroin words, suggesting that the moderation of the attentional bias was at least somewhat specific. Clearly this is a preliminary finding (small sample size; $n=18$ ), but it could give rise to further investigations of effects of medications on implicit drug-related cognition.

The findings on attempts to change a drug-related attentional bias can be summarized as follows: there is ample evidence for the existence of an attentional bias for drugs of abuse, in drug users and misusers, confirmed for different drugs of abuse using different experimental tests. Less is known about whether this attentional bias can be found outside conscious awareness as has been found for threat stimuli in anxious patients (e.g., Franken et al., 2002). Although the idea expressed in many papers on the subject is that the attentional bias should be strongly correlated with craving, these correlations are often but not always found (see Franken, 2003, for a review). A small number of recent studies has aimed at changing an attentional bias in therapeutic settings, and preliminary evidence indicates that measures of attentional bias can be changed by a dopamine antagonist (Franken et al., submitted for publication) and a nicotine patch (Waters et al., 2003), and that measures of attentional bias can be predictive of clinical outcome (Cox et al., 2002; Waters et al., 2003). 


\section{HOW TO CHANGE IMPLICIT ASSOCIATIONS: SOCIAL COGNITION RESEARCH}

The social cognition research most relevant here investigated the malleability of implicit attitudes. A great deal of this work was completed within the specific arena of research on stereotyping and prejudice. Implicit attitudes can be assessed with a variety of tests, including affective and semantic priming, the Implicit Association Test (IAT) and recent varieties such as the (EAST) and The Go/No-Go Association task (GNAT) (Nosek and Banaji, 2001; see also the Appendix). In these tests, reaction times to words from one category (e.g., Black faces) are compared when they are given in association with positive or negative words. When reaction times are faster for the Black-Negative association then for the Black-Positive association, this is interpreted as the expression of an implicit negative attitude toward Blacks (see Fazio and Olson, 2003; Greenwald et al., 1986; the Appendix). Typically, correlations between implicit and explicit measures are small but not zero (for a review, see Dovidio et al., 2001). Perhaps more problematically, different implicit measures also correlate only modestly (e.g., Bosson et al., 2000). However, this may be at least partly due to relatively large measurement errors: once these are accounted for in structural models, the different tests of implicit associations were found to load on a common factor, and the explicit measures on a different factor (Cunningham et al., 2001). Another possibility is that different tests assess different aspects of implicit cognition (Olson and Fazio, 2003), or different underlying (sub)processes (referred to later).

Several studies have reported that implicit and explicit measures of stereotypical attitudes predict different aspects of behavior: implicit attitudes better predict automatic behaviors of which participants are not aware (e.g., distance to a job candidate), whereas explicit attitudes better predict controlled behavior (Dovidio et al., 2001). Given this differential prediction of different aspects of behavior, recently researchers in social cognition began to investigate how to change implicit attitudes, mostly in the domain of automatic stereotyping.

In a series of experiments examining the effects of extensive training in the negation of stereotypic associations (press the "NO" button for stereotypical associations), it was found that this procedure could result in a diminished automatic activation of negative stereotypes (Kawakami et al., 2000). Interestingly, this was observed after extensive training only (480 trials of negating the stereotypic associations) and not after explicit instruction not to stereotype with only limited practice (80 trials). In a second study, the authors found that the reduction in 
automatic stereotyping lasted at least $24 \mathrm{~h}$ (second test time), and in a third study similar results were found for racial stereotypes, even after performing a task that activated stereotypes.

In another recent study participants were exposed to a less intensive counter-stereotypical exemplars technique (40 exemplars) (Dasgupta and Greenwald, 2001). It tested whether this procedure would influence implicit racial attitudes as assessed with the racial IAT (Greenwald et al., 1998). White and Asian participants first completed a task that was ostensibly a measure of general knowledge. They were exposed either to a series of admired Black and disliked White individuals (pro-Black condition), or to admired White and disliked Black individuals (proWhite condition). Pictures came with the name of the individual (e.g., Martin Luther King) and either a correct or an incorrect description. Participants' task was simply to indicate whether the description was right or wrong. Implicit racial attitudes were assessed directly after this test and again $24 \mathrm{~h}$ later. The pro-Black condition resulted in a significant decrease of the implicit negative attitude toward Blacks, as compared both with the pro-White and with a neutral control condition. The effect was found both directly after exposure to the counter-stereotypical exemplars and $24 \mathrm{~h}$ later. Interestingly, this intervention did not affect the explicit racial attitudes (semantic differentials and feeling thermometers). In a second study, similar results were found directly after counterstereotypical exemplars of admired old people, which reduced the implicit preference for young people among university students, adding to the generalizability of the finding.

Another set of experiments (Blair et al., 2001) tested the effects of counter-stereotypical mental imagery on implicit gender stereotypes (of weak women vs. strong men). Across five studies, Blair and colleagues demonstrated that counter-stereotypical mental imagery (imagine a strong woman) significantly reduced implicit gender bias, across different implicit measures (IAT, GNAT, and False Memory Test), and in comparison with different control conditions (including no imagery, stereotypical mental imagery, unrelated mental imagery, and the instruction to explicitly try to suppress female-weakness associations).

A recent study found that a brief evaluative conditioning procedure influenced implicit self-esteem and behavior (e.g., maintaining a boring task) (Dijiksterhuis, 2004). An evaluative conditioning procedure was employed, in which participants in the experimental condition were repeatedly exposed to the combination of I with positive words (as compared with combinations with neutral words or with an $\mathrm{X}$ instead of I). The consistent finding across a series of experiments was that this brief manipulation (three minutes) had a positive effect on implicit self-esteem 
and related behavior, even when both the prime (I) and the positive words were presented so briefly that they could not be detected (subliminal presentation).

The studies described so far show effects on implicit stereotype activation, but the methods used are very different from methods commonly used to counteract stereotypical behavior. We found two studies that used existing interventions that targeted racial prejudice and studied the effects on implicit and explicit racial attitudes. Rudman and colleagues (2001) studied the effects of an existing diversity training (prejudice and conflict seminar, taught by an African American professor) on implicit and explicit racial attitudes. This quasi experiment (controls were recruited from a methods class, hence no random assignment to conditions), found that the training reduced both implicit and explicit prejudice toward Blacks in White students. Interestingly, changes in implicit and explicit prejudice measures were associated with different process-measures assessed after the diversity training: a cognitive process measure correlated significantly with changes in explicit prejudice, but not with changes in implicit prejudice, whereas a more affective process measure correlated significantly with the changes on all of the implicit measures used, but not with the changes on the explicit measures. This study shows that different aspects of a real world intervention, may have differential impact on implicit and explicit prejudice, and, encouragingly, that both can be changed.

Another recent study (Maio and Watt, submitted for publication) tested the effects of British antiracism messages (e.g., posters stating: Multicultural $=$ prosperity + progress $)$ on implicit and explicit racial attitudes, as assessed with a subliminal priming paradigm (outside awareness of the participants). The experimental manipulation was set up to closely match natural exposure to such an advertisement. Participants were instructed to count words of the Table of Contents in a magazine with either the antiracism or a control advertisement on the page next to the Table of Contents. It was found that the antiracism advertisements increased implicit prejudice in ambivalent participants, while decreasing implicit prejudice in nonambivalent participants. Unfortunately, this study suggests that antiracism advertisements with a simple persuasive message may have a negative influence on ambivalent people who need the message the most.

One other area of social cognition research should be briefly mentioned because of its potential value for prevention (even though it is not directly concerned with changing implicit cognition): recent work on automatizing and unconscious control (e.g., Bargh and Chartrand, 1999; Gollwitzer, 1999). The basic idea in these models is that when 
somebody repeatedly performs a behavior in a particular context, intentions and actions may become automatically triggered in memory. These may constitute undesirable behaviors that are difficult to change (e.g., smoking in a bar), but also more healthy alternatives. Consequently, the latter should be practiced in the relevant context, and this may make the healthy alternative more effortless and automatic (these suggestions are close to those from a learning psychology perspective, but are more cognitively colored). From this perspective, cognitive rehearsal of implementation intentions may also result in desirable changes, in the absence of real experience. It is further suggested that behavior change of habits will involve conscious cognitive dismantling of unconsciously activated habits and replacement by practice of alternative behavioral sequences.

Taken together, recent studies in social cognition demonstrate that implicit prejudice and implicit self-esteem are more malleable than previously thought, across a variety of experimental manipulations and implicit assessment techniques. In several studies differential effects were demonstrated on implicit and explicit measures and changes in implicit and explicit prejudice were predicted by different moderating variables (Dasgupta and Greenwald, 2001; Maio and Watt, submitted for publication; Rudman et al., 2001). Additionally, different experimental techniques were used to change implicit associations: experimental techniques such as the presentation of a large number of counterstereotypical associations, or exposure to or mental imagery of counterstereotypical exemplars, evaluative conditioning, and attentional retraining. In addition real world interventions were tested for their effects on implicit and explicit cognitions. It should be noted that the effects of the real world interventions on implicit cognitions were positive in one study (Rudman et al., 2001), and negative in another study (Maio and Watt, submitted for publication). The effects of the manipulations have been studied in short time intervals, either directly after the experimental manipulation or $24 \mathrm{~h}$ later (Kawakami et al., 2000), or two days later (Maio and Watt, submitted for publication). The first two studies still showed effects after $24 \mathrm{~h}$, but these were not found two days later in the latter (but of course this one negative finding does not imply that changes over a longer period than $24 \mathrm{~h}$ are not possible). Overall, these studies suggest that including implicit measures in effect-studies of both experimental and existing interventions may be beneficial, because both desirable and undesirable effects may appear both on implicit and explicit measures. Increasing our understanding of these effects may help to improve interventions, as might studies of automaticity in behaviors. 


\section{How to Change Implicit Drug-Related Associations}

In social cognition research, associations are typically assessed in one affective dimension only (pleasant-unpleasant, or valence), which is related to the aim to measure implicit attitudes (or global evaluations). However, when applied to psychopathology, it may be useful to include other dimensions. For example, fear-specific implicit associations were more strongly related to phobic anxiety than the more general implicit attitudes (implicit associations between spiders and positive vs. negative) (Teachman et al., 2001). With respect to substance use and misuse, Wiers and colleagues found that heavy and light drinkers did not significantly differ with respect to their implicit attitudes toward alcohol on the valence dimension, but that heavy drinkers showed alcohol-arousal associations that light drinkers did not show (Wiers et al., 2002). The alcohol-arousal associations of heavy drinkers could reflect a sensitized psychomotor stimulant reaction, which occurs with repeated drug use, in line with incentive sensitization theory of addiction (Robinson and Berridge, 1993, 2001, 2003). Since then, the alcohol-arousal associations were replicated by ourselves in heavy drinkers (Wiers et al., submitted for publication) as well as by another research group in alcoholics in treatment (De Houwer et al., unpublished manuscript).

In a recent follow-up study (Wiers et al., 2003; submitted for publication), 92 heavy drinkers were randomly assigned to an expectancy challenge procedure (Darkes and Goldman, 1993), which aims to change positive arousal expectancies, or to a sham alcohol experiment in the same bar lab (to control for context-effects). Implicit and explicit alcoholrelated cognitions were assessed a week before and a week after the experiment. As hypothesized, participants in the expectancy challenge condition showed a significant reduction in their arousal expectancies as compared with the controls, when measured explicitly on a self-report questionnaire. What happened with the implicit associations? Again heavy drinkers showed significant implicit negative alcohol associations and implicit alcohol arousal associations (both at T1 and at T2), but the intervention had no significant effect on these associations. Of course this negative finding could be related to the specific measures used, but we think this is unlikely given that the test-retest reliability of both IATs was rather good (.7), and that another recent study (Teachman and Woody, 2003) reported that implicit fear-specific associations, as assessed by the IAT, can be altered after treatment (underscoring the validity of the IAT in assessing clinically relevant change). These considerations led us to conclude that the most likely explanation of the results was that the intervention differentially affected explicit and implicit alcohol-related 
cognitions. From that conclusion, we began to ask ourselves how one could more successfully change implicit alcohol-related cognitions, which was the starting point for this article.

From a cognitive motivational point of view (Cooper et al., 1995; Cox and Klinger, 1988), it has been argued that there are (at least) two different types of alcohol misusers: individuals who use alcohol to increase positive affect (positive reinforcement: enhancement drinkers) and individuals who use alcohol in order to feel less bad (negative reinforcement: coping drinkers). ${ }^{4}$ Zack and colleagues (1999) compared the alcohol-anxiety associations in problem drinkers with and without anxiety problems using a semantic priming task. They found that only in problem drinkers with high levels of anxiety, lexical decisions (word or nonword) for alcohol-related words were primed by words of negative affect, indicating automatic association of negative affect with alcohol use. Stewart et al. (2002) selected social drinkers scoring either high on coping motives (CM) or scoring high on enhancement motives (EM). The primed Stroop test used consisted of three types of primes: positive affect words, negative affect words, and neutral words (house-related nouns). Targets were alcoholic drinks or neutral words (clothes). As expected, CM-drinkers were slower to mention the color of an alcoholic target word than a neutral target word when it was preceded by a negative mood word. This difference was not found for EM-drinkers. Also in accordance with the hypotheses, EM-drinkers were slower to color-name alcoholic target words than neutral target words when they were preceded by a positive affect word. Unexpectedly, CM-drinkers showed the same priming effect for positive affect words. If proven valid, this finding could indicate that all drinkers first learn to associate alcohol with positive emotions (Goldman et al., 1987), and that later on a subgroup of drinkers learns coping-related motives when a negative mood and alcohol use are associated. This second development may be a specific risk factor for developing alcohol use related problems over and above heavy drinking per se (perhaps in a subgroup of individuals scoring high on anxiety), but future longitudinal research should critically test this idea. A recent study found that negative mood primed alcohol targets in university freshmen, both in participants scoring high and in

\footnotetext{
${ }^{4}$ Note that these categories are not mutually exclusive: an individual can use or misuse substances for both reasons. Note further that for alcohol use other motives have been found, such as social drinking, and that for alcohol misuse many different taxonomies have been proposed, relating to the perspective of study (e.g., genetic, developmental, treatment, etc.).
} 
participants scoring low on anxiety sensitivity, which may suggest that it is to some extent a general acculturated idea that drinking alcohol follows being in a bad mood (Zack et al., 2003). Interestingly, in women but not in men, these primed responses predicted self-reported drinking in bad moods, suggesting that in women this association is more related to their own behavior. From the present perspective, it will be particularly interesting to investigate whether the negative affect-drug associations can be modified. One quasi-experimental study investigated this issue (Zack et al., 1999). It was found that unmedicated anxious problem drinkers showed significant facilitation of alcohol targets by negative affect primes (as in the other studies), and that anxious problem drinkers who took their regular doses of benzodiazepines did not show this facilitation. Taken together, these studies indicate that it may be useful to differentiate between different subtypes of problem drinkers, when assessing implicit cognitions. It is an interesting question to what extent this also applies to smoking and other drug use. Further, one may question how the implicit associations between a negative mood and alcohol relate to the implicit alcohol-arousal associations we and others have found in heavy drinkers (De Houwer et al., unpublished manuscript; Stewart et al., 2003; Wiers et al., 2003; submitted for publications). And of course the most relevant question here is to what extent these different implicit associations with substances of abuse can be modified. In summary, the number of studies in which drug-related implicit associations are targeted for change is very small, with one negative finding concerning change in implicit associations for a cognitive behavioral intervention that successfully changed explicit cognitions (De Houwer et al., unpublished manuscript; Wiers et al., submitted for publication), and one quasi-experimental medication study showing a (between-subjects) effect of medication (benzodiazepines) on implicit alcohol-negative affect associations. Clearly more research is needed in this area.

\section{CHANGING IMPLICIT (DRUG-RELATED) COGNITIONS: GENERAL ISSUES}

At first glance, the reviews from the different areas of research discussed (summarized in Table 1) may give the impression of leading to opposing conclusions: on the one hand, experimental learning psychology and memory research suggest that learned associations and implicit memories are resistant to change (Baeyens et al., 1995), and on the other hand, research in experimental psychopathology and social cognition 
suggests that both attentional biases and implicit associations can be changed. How can these findings be reconciled? Before attempting to integrate these findings, it seems important to first reconsider what exactly is measured (and targeted for change), in the different traditions.

\section{Specific and Global Representations}

Our review of the memory literature indicated that it may be important to distinguish perceptual, more specific memories from more global conceptual memories (Barsalou, 1999; Barsalou et al., 2003; Damasio, 1999). When one considers this distinction, the two seemingly opposing conclusions may be reconciled: a global conceptual representation consists of a number of more specific associations. Even when it is true that the specific representations cannot be changed, the more global representation may be subject to change: new specific associations can be added and the relative weight or accessibility of different representations can change through new experiences.

The question then becomes one of how we should view these global representations and attitudes? They can be thought of as a momentary construction of underlying specific memories and representations (Barsalou, 1999; Barsalou et al., 2003; Mitchell et al., 2003) or as more stable higher order representations that are stored in long term memory (e.g., Fazio, 1990; Greenwald et al., 1998). In psychology and the neurosciences there has been a long-standing debate about the nature of mental representation, where one view focuses on mental representations as things that can be located (e.g., Hebb, 1946; McClelland and Rummelhart, 1985; Mitchell et al., 2003; Penfield and Welch, 1951; Wiers, 1992) and retrieved and another view is that mental representations are distributed patterns of activation. In this second view, more conceptual memories are not stable things, but rather are patterns of activation (of specific memories) that will differ as a function of context, previous experience, etc. In essence, each time a global evaluation is assessed, it is (re)constructed on the spot (Mitchell et al., 2003; Stacy et al., in this issue). From this perspective, global representations can be viewed as being reenactments that use the original modality-specific states but which are imperfect and may contain distortions (Barsalou, 1999; Barsalou et al., 2003). Mitchell and colleagues (2003) demonstrated in a series of experiments that an implicit attitude can be positive or negative, depending on cues in the environment that trigger one classification or the other. For example, when comparing black women and white man, the most salient categorization (male-female or 
ORDER

1654

Wiers et al.

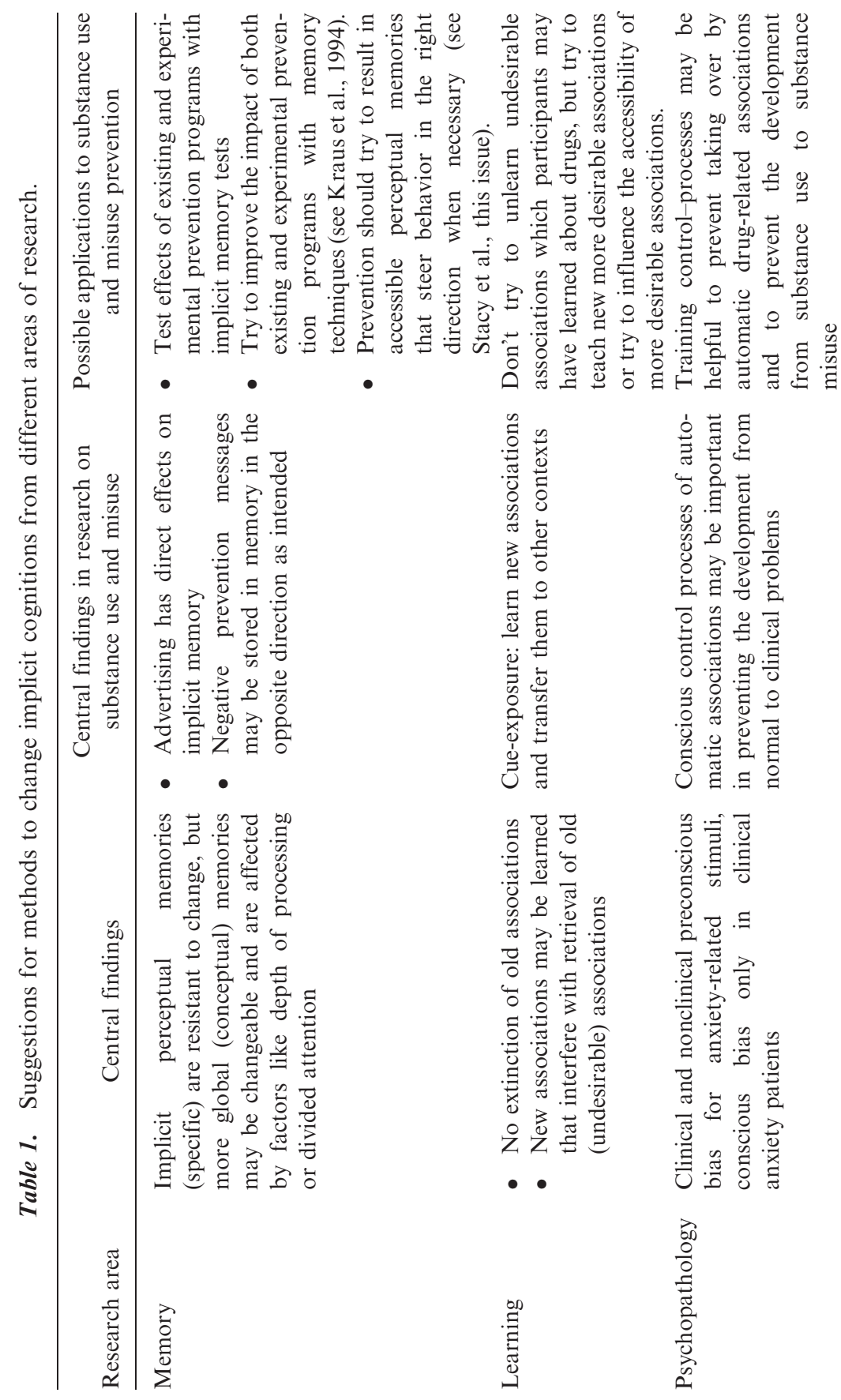


ORDER

Can Implicit Drug-Related Cognitions Be Changed?

1655



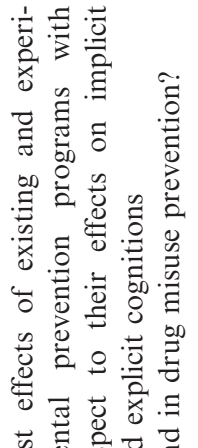

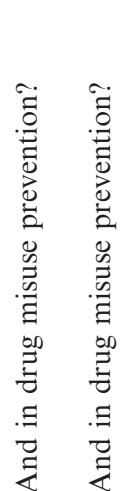

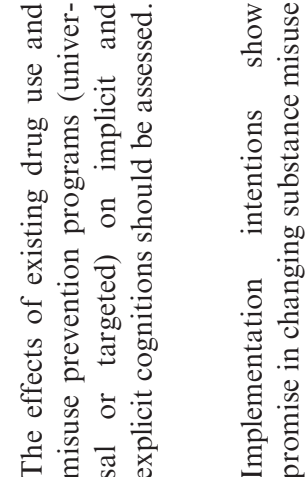

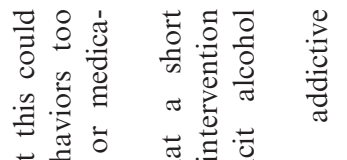

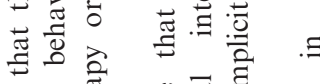

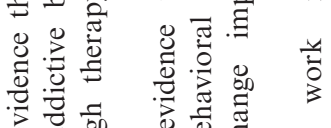

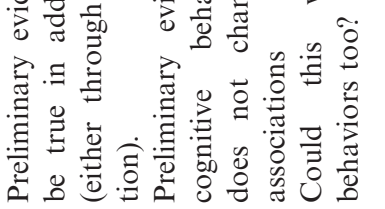

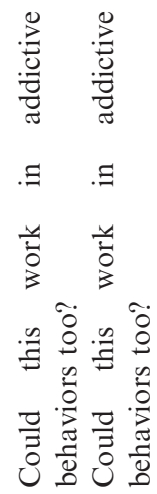

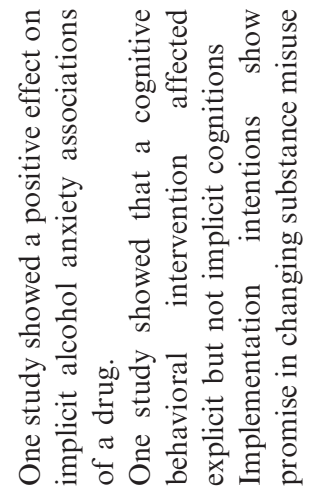

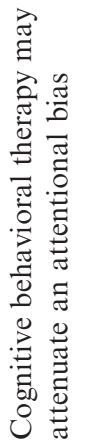

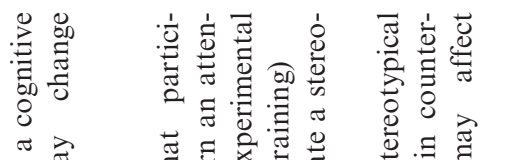

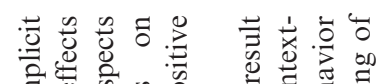

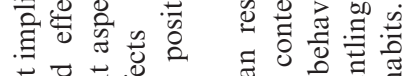

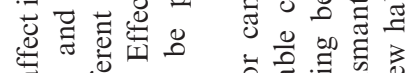

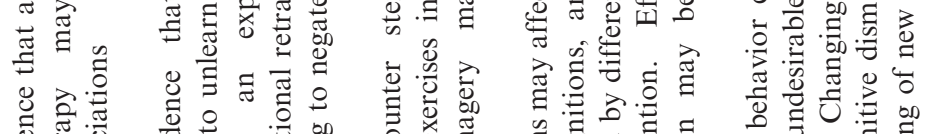

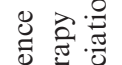

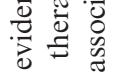

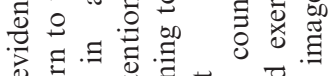

药

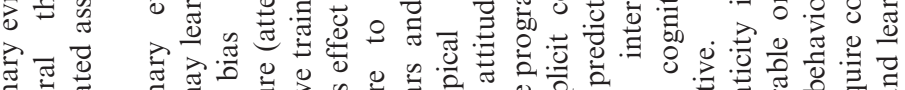

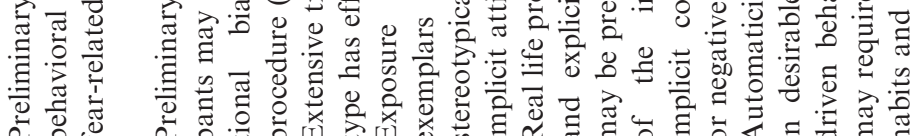

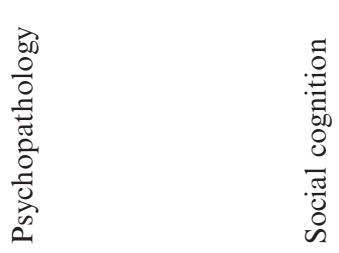


Black-White) will determine the attitude to that group (women and white people are generally favored over men and Black people). An interesting finding was that this could be manipulated with relatively subtle context cues (e.g., stimuli that the participant had to ignore in the GNAT, see Appendix), and that participants could not predict their context dependent changes in attitudes. The authors note that the inability to predict the malleability of their attitudes may help to explain the pervasiveness of the view that attitudes are inherently inflexible and stable (from this perspective the idea that global representations are stable things could be viewed as a naïve theory).

An alternative explanation could be that both forms of representation coexist: after repeated activation of a global evaluation, this evaluation could be rerepresented in a different higher order neural system (e.g., Edelman, 1990) as a more stable explicit global attitude. In this view, people can hold dual attitudes (cf., Wilson et al., 2000): a dynamic ever changing pattern of activation that is assessed with implicit measures (and that may change as a function of the implicit assessment, hence low correlations between implicit measures are not unexpected from this perspective), and a more stable rerepresentation of the underlying pattern of activation that is assessed with explicit measures. Note that this view leads to the opposite prediction as the view that inspired much work on implicit assessment, the bonafide pipeline view (Fazio et al., 1995; Greenwald et al., 1998, 2003): from this perspective implicit measures may better assess the real underlying attitude, that would be less influenced by self-presentation strategies than explicit measures. The ideal implicit measure would tap into the platonic underlying real attitude, that should be stable across different situations. From the constructivist reenactment perspective the dynamic pattern is inherently unstable and dynamic and the search for the ideal implicit assessment strategy may be in vain (cf., Barsalou et al., 2003; Blair 2002; Mitchell et al., 2003). The important question for both theoretical and practical purposes is whether explicit measures tap into a separate rerepresentation and, if so, to what extent these higher order global representations differentially affect behavior.

The representations targeted in the areas of experimental psychopathology and social cognition research are typically of the more global nature (e.g., spiders, self-esteem, Blacks). The global representation will consist of a lot of specific associations that may vary in valence (e.g., regarding smoking, the sensory experience, the negative health consequences illuminated on the package, a memory of smoking with a lover). Different contexts may activate different aspects of the global memory representation (Barsalou, 1999; Mitchell et al., 2003). In line 
with this idea, Sherman et al. (2003) found that smokers' implicit attitudes differed between a context in which the sensory aspects were central and a context in which the negative health aspects were central.

From the present perspective, an intervention may result in changes in the overall global evaluation of an attitude object by adding new associations and by changing the relative ease of activation of different aspects of the global representation, even when the intervention may not result in an extinction of a specific aspect of the original representation. Hence, the tentative conclusion from this integrative review is that it may be hard or even impossible to change specific (drug-related) associations, but that the global pattern of (drug-related) associations is more malleable (or even inherently malleable). If the global representation assessed with explicit measures is also constructed on the spot, the same should apply for explicit global attitudes and associations (Schwartz, 1999), but if they tap into separate (rerepresented) entities, interventions may differentially affect implicit and explicit representations (e.g., a subtle manipulation may affect the implicit pattern of activation, but not the explicit global representation).

\section{Attentional Bias vs. Implicit Associations: Conceptual and Measurement Issues}

Research in experimental psychopathology (including substance use and misuse) has so far primarily studied psychopathology-related attentional biases and how interventions may change these attentional biases, while research in social cognition has primarily studied implicit attitudes and ways to change them. When studying effects of interventions on implicit cognitions it is important to consider the instruments used. In studies of attentional bias, one measure may predict treatment outcome, while another measure may not find this, and this could be related to the different aspects of attention tapped by various measures (Fox et al., 2001; Mogg et al., 2003; Waters et al., 2003). With respect to the assessment of implicit attitudes, different instruments may measure different aspects of an implicit attitude. For example, in the Implicit Association Test (IAT) the global category level (e.g., smoking) seems more important than specific exemplars used (De Houwer, 2001; but see Mitchell et al., 2003). When one is interested in assessing associations for specific exemplars, other tests may be better suited (e.g. the EAST) (Wiers et al., 2003, see further the Appendix here and Wiers and DeJong, in press). However, it is not always evident beforehand which level of description is best suited. Are we interested in a heavy drinker's general 
attitude to drinking alcohol or more specifically in the attitude regarding margaritas, their favorite drink? It may be beneficial to use personalized stimuli (Cox et al., 2002), both with respect to the measurement of attentional bias and implicit associations and in cue exposure And this may well go beyond assessment: recent studies have indicated that tailoring (personalizing prevention messages) may be beneficial with respect to behavioral outcomes (e.g., Dijkstra et al., 1999). Further, individual first associations as measured with paper and pencil measures (e.g., Stacy, 1997) may assess different aspects of implicit cognitions than implicit associations on standardized tests of speeded performance, such as the IAT or the EAST, but this speculation clearly requires empirical testing. Similarly, the reviewed studies in social cognition reported changes in a variety of implicit measures, but the few studies in the clinical domain primarily used the IAT (Teachman and Woody, 2003; Wiers et al., 2003; submitted for publication), except one quasi-experimental study that used semantic priming (Zack et al., 1999).

Apart from these measurement issues for both constructs, one may question the relationship between attention and implicit cognition. Some recent evidence suggests that some minimum level of focused attention is necessary to produce implicit associations: several experiments now show that when the attentional load necessary for a second task is higher, fewer stereotypic word completions are observed following subliminal exposure to black faces (see Blair, 2000, for a review), which is the opposite finding as would be predicted from the bonafide pipeline view on implicit assessment. In a similar vein, a recent series of experiments demonstrated that affective priming with pictures only works when participants have to use semantic information (use the name of the picture) (Spruyt et al., 2002). Further, the occurrence of an implicit memory bias in depression critically depends on conceptual processing (Watkins, 2002). These findings are consistent with general models of representation that suggest that some minimum level of selective attention is necessary for the activation of global concepts (Barsalou, 1999; Barsalou et al., 2003). From these findings one could conclude that the term implicit in implicit cognition cannot be equated with unconscious (cf., Greenwald and Banaji, 1995). However, it should be noted that there is rather robust evidence for the existence of perception without awareness (e.g., stimuli that are presented so briefly that they are not consciously detected), which influences which subsequent stimuli are perceived with awareness and how these are perceived (Merikle, et al., 2001). Hence, the activation of global concepts may sometimes be a bottom-up process that is triggered without awareness but some level of attention may be necessary to observe effects of the activation of the global concept. 
In the area of substance use and misuse, both a drug-specific attentional bias (e.g., Franken, 2003) and implicit arousal associations (Wiers et al., 2002) have been related to the incentive sensitization theory of addiction (Robinson and Berridge, 1993, 2001, 2003). The reader may wonder whether the attentional bias and implicit arousal association constructs are equivalent. In our view, they represent different aspects of a sensitized response to drugs of abuse: an attentional bias represents the preferential allocation of attention to alcohol- or drug-related stimuli and the drug-arousal associations represent the preparatory appetitive approach response that follows. In line with this idea (Palfai and Ostafin, 2003), it has been found that heavy drinkers showed significant alcoholapproach associations (contrasted in an IAT with alcohol-avoidance associations), and that these implicit approach associations correlated with an urge to drink alcohol after cue exposure, but not with an urge to drink in a neutral condition. Several researchers have linked a drugrelated attentional bias to an appetitive response (Baker et al., 1987; Bradley, 2002; Franken et al., 2002, 2003; Mogg et al., 2003), and this is sometimes related to affective valence or perceived attractiveness of drugrelated stimuli (e.g., Mogg et al., 2003). Robinson and Berridge (2003, 1993, 2001) theorize that the dopamine-mediated incentive salience response to drugcues is related to wanting, rather than to liking, and that in the case of addiction these processes that normally go together dissociate: addiction comes with compulsive wanting, even when the individual does not like his or her addiction anymore (which is not unlikely to happen, given the many negative consequences associated with addiction) (see also Jones and McMohan, 1998). We hypothesize that the extent to which a drug-related stimulus gives rise to an automatic appetitive response is related to craving, and that automatic appetitive response may be assessed through implicit arousal associations (Wiers et al., 2002) or implicit approach associations (Palfai and Ostafin, 2003) and that this may occur even for disliked stimuli such as ashtrays. In fact, several studies now find primarily negative implicit associations for smoking (Huijding et al., submitted for publication; Rudman, 2004; Swanson et al., 2001; Wiers and DeJong, in press). In our view, subjective craving occurs when this approach tendency comes to consciousness (e.g., when it is impossible to approach the drug of abuse, but blocking of an automatized need not be a necessary condition for the occurrence of craving (Tiffany, 1990). Obviously, to what extent these constructs are really different should be empirically tested (attentional bias vs. implicit associations), how they relate to subjective craving, to physiological measures of appetitive responses (e.g., Mucha et al., 1999), and to druguse behavior. 


\section{How Do Implicit (Drug-Related) Cognitions Originate?}

As noted earlier, different views exist concerning dissociations between implicit and explicit cognitions: one focusing on measurement (Fazio and Olson, 2003); for a similar argument related to drug use (Goldman et al., 1999), and another viewing them as representing different neural processes (e.g., for a similar argument related to drug use, see Stacy, 1997; Wilson et al., 2000). One way implicit associations can originate is through classical or evaluative conditioning, even in the absence of awareness of the pairing of stimuli (Olson and Fazio, 2001). Further, implicit associations can originate even after minimal manipulations (Ashburne-Nardo et al., 2001), and the same has been reported for evaluative conditioning (De Houwer et al., 2001). In Barsalou's general theories on representation, the emotional component also constitutes an important aspect of the global representations (Barsalou, 1995; Barsalou et al., 2003). There is some preliminary evidence suggesting that affective experiences are more likely to influence implicit than explicit associations. In a recent series of studies, Rudman and colleagues (Rudman and Heppen, submitted for publication; see also Rudman, 2004), found that negative implicit smoking associations are related to (mostly negative) retrospectively reported early experiences with smoking, while positive explicit attitudes are related to recent (more positive) experiences. In a second study, they found that reading a guiltinducing newspaper article (about negative consequences of smoking for loved ones in the direct environment) made smokers' implicit associations more negative, without affecting their explicit attitudes. Again, this finding seems in line with the idea that the implicitly assessed attitude is more malleable due to the more dynamic underlying representation and that the explicit attitude is a more stable rerepresentation. The reviewed studies in social cognition research on changing implicit attitudes also showed that affective experiences were primarily related to changes in implicit attitudes, while cognitive experiences were primarily related to changes in explicit attitudes (Dasgupta and Greenwald, 2001; Rudman et al., 2001). Clearly, more developmental research is needed, focusing on the origins of implicit and explicit drug-related cognitions (see also Chassin et al., 2002).

What happens in the development of drug-related cognitions? Using explicit measures of alcohol expectancies, Wiers and colleagues found that before they initiated drinking alcohol themselves, all children were negative about alcohol and that children of alcoholics were even more negative than other children (Wiers et al., 1998). However, when children of alcoholics and children of nonalcoholics were compared after they 
had initiated alcohol use, children of alcoholics were more positive. Moreover, a similar difference was still found in alcoholic patients: those who had an alcoholic parent themselves scored higher on positive arousal expectancies for a high dose of alcohol than in those who did not have an alcoholic parent themselves, and this association was mediated by their scores on impulsive personality disorders (cluster-B) (Wiers et al., 2000). Taken together, a picture emerges in which children are negative about alcohol, and probably about cigarettes and other drugs too, based on negative personal affective experiences (smell of cigarettes, drunk people) and on what is taught in society (drugs are bad). We expect no difference between implicit and explicit measures at this stage. Once an individual has initiated use (under influence of peer pressure and/or other factors), this will give rise to a series of affective experiences that are mediated by genetic factors influencing individual differences in physiological reactions to the drug (McGue, 1999). With repeated use, the initial psychomotor stimulant reaction shows sensitization (Berridge, 1993; Robinson and Berridge, 2001, 2003) and this stronger stimulusresponse relationship may be stored in memory as implicit drug-arousal associations (Wiers et al., 2002), and may give rise to a drug-specific attentional bias (e.g., Franken, 2003). As substance use progresses to misuse and abuse, more negative associations will develop (Jones and McMohan, 1998), and we speculate that these may develop both on the implicit and on the explicit level. From this perspective, it does not come as a surprise that substance users can be negative about their drug of abuse, both on implicit and explicit measures but continue to use and misuse their drugs, which may be driven by an attentional bias and/or drug-related implicit arousal associations. This view may be related to Kahneman's findings that man's judgments and decision making are alltoo-often anchored in irrational rather than in rational thought processes (work for which he received the Nobel prize). In his Nobel lecture, Kahneman argued that the automatic or implicit associative system is the default system affecting human decisions (Kahneman, 2003). Applied to substance misuse, the fast associative implicit cognition system may promote continued drug use, even when the slower rational system promotes stopping.

\section{HOW TO CHANGE IMPLICIT DRUG-RELATED COGNITIONS IN PREVENTION}

What follows from this integrative review with respect to research on the prevention efforts in general, and of substance use and misuse in 
particular? First, it should be noticed that as yet, very few studies have measured effects on implicit cognitions in a context more or less directly related to prevention. The few studies that did, often reported different effects of a preventive intervention on implicit and explicit measures. These variable effects have ranged from:

- A positive effect on implicit measures in the absence of an effect on explicit measures (regarding stereotyping) (Dasgupta and Greenwald, 2001).

- A positive effect on explicit measures in the absence of an effect on implicit measures (regarding alcohol misuse (Wiers et al., submitted for publication; Wiers et al., 2003).

- A negative effect on implicit measures (no explicit measurement, regarding facts and myths about alcohol) (Krank and Swift, 1944).

- A positive effect on implicit measures (no explicit measurement, both regarding stereotyping) (Blair et al., 2001; Kawakami et al., 2000).

- A negative effect on implicit and explicit measures, moderated by different variables (regarding stereotyping) (Maio and Watts, submitted for publication).

- A positive effect on implicit and explicit measures, moderated by different influences (regarding stereotyping) (Rudman et al., 2001).

In summary, interventions can have differential effects on implicit and explicit cognitions, both in the intended and in the unintended direction. Clearly, the only way to find out what the effects are, is by measuring them, with implicit and with explicit measures both included, and this will advance theory about how these cognitions can be modified.

Second, when considering universal prevention, implicit memory research may be relevant with respect to the way in which preventive messages are framed (for a more elaborate discussion on this topic, see Stacy and Ames, 2001). For example, using negations in preventive messages may result in unintended effects (Krank and Swift, 1944). Primary school children are generally already very negative about alcohol and drugs; therefore, it is questionable to what extent it is beneficial to try to make children more negative at this age (cf., Kraus et al., 1994; Wiers et al., 2000), and preliminary results indicate that they are less influenced by alcohol advertisements than are children who have started drinking (Krank and Kreklewetz, 2003). Further, it is important to investigate factors promoting the initiation of alcohol and cigarette use (typically in the early teenage years), and to what extent these factors influence the 
beginning of use through explicit and/or implicit cognitions: perhaps these cognitions mediate other influences and constitute a final common pathway (Goldman, 1999; Goldman et al., 1999). It could, for example, be a better plan to focus on strategies that are not specifically related to alcohol or drugs before alcohol or drug use is initiated. Research in experimental psychopathology has indicated that training of executive control processes may be helpful to prevent the development of externalizing psychopathology, that is also thought to be related to the development of substance misuse (see also Bechara et al., 2000; and footnote 1). In addition, a number of factors outside of the realm of implicit cognition may be most relevant at this point (e.g., preventing school dropout, developing friendships), but these fall outside of the scope of this article.

Third, most of the interventions discussed here seem most suited to targeted or indicated preventive interventions: targeting individuals who already use or misuse drugs. The research reviewed here suggests that there may be differential ways to influence implicit and explicit cognitions, and that these may both contribute to behavioral change in the desired direction. This observation leads to the question how one may change implicit and explicit drug-related cognitions in drug users.

\section{How Can One Change Explicit Drug-Related Cognitions Or... Their Effects On Substance Misuse?}

On a very general level, one recommendation to change implicit cognitions is to start by changing behavior in the desired direction, and the implicit cognitions will follow experience and may help to maintain the change (cf., Wilson et al., 2000). However, in the case of substance misuse, it is well known that it is not easy to begin to change behavior. What more can we offer than the advice to change the behavior and that the cognitions will follow?

First, it is important to investigate the effects of existing interventions on implicit and explicit cognitions. One method that has been developed for young problem drinkers is the expectancy challenge, for which some positive results have been reported (Darkes and Goldman, 1993, 1998; Jones et al., 2001). A second promising method is through motivational interviewing (Dimeff et al., 1999; Marlatt et al., 1998; Miller and Rollnick, 2002). Some of these existing interventions may have effects on implicit cognitions, despite our own recent negative finding regarding implicit cognition measures for an expectancy challenge (Wiers et al., 2003; submitted for publication). As far as we know, there have been no other 
studies that have investigated the effects of either approach on implicit vs. explicit cognitions. Motivational interviewing, for example, could well affect implicit processes, given that personally relevant affective experiences and personal concerns are targeted. Further, in many cognitive behavioral approaches (e.g., Beck et al., 1993), behavioral strategies are discussed that may be employed to successfully change behavior. These speculations clearly await empirical verification. One outcome could be that different aspects of cognitive behavioral (or other) interventions successfully moderate implicit vs. explicit drug-related cognitions. But outcomes may be less positive too, and investigating implicit and explicit cognitions in this context may lead to suggestions for improved targeted preventions.

Second, the present transdisciplinary review indicated that it may be important to distinguish between specific implicit cognitions, and more global ones, and that the finding in different fields that specific implicit cognitions are difficult or impossible to change, does not imply that the more global cognitions are immune to change. Supplementing effect studies with more implicit measures' cognition and memory may be beneficial to more completely assess intervention effects, and for deriving ways to improve these prevention programs, in such a way that the more global representations are changed in the desirable direction.

Third, this integrative review documents that in different areas of experimental psychology (especially in social cognition and experimental psychopathology research, see Table 1), show that new experimental methods have been developed and tested that are aimed at changing implicit cognition, and these methods could be tested in the area of drugprevention research as well. With respect to an attentional bias, recent studies on attentional retraining indicated that participants can learn to move their attention away from threatening stimuli, and preliminary evidence indicates that this procedure could even have an impact on clinically anxious patients, with effects comparable to an established cognitive behavioral intervention. A challenging question exists about the extent to which this idea can be used in research on substance misuse, in treatment as well as in planned targeted interventions: can substance misusers be taught to automatically move their attention away from the psychoactive substance of misuse? And if this can be done, what are the empirically based critical and necessary conditions, will it affect behavior, and for how long?

Similarly, research in implicit cognition has indicated that global implicit cognitions regarding stereotypes and self-esteem can be changed in a number of more or less orthodox ways (ranging from 
existing antiracism programs to subliminal affective priming). It should be noted that the reported changes were tested only in the short term, either directly after the manipulation or $24 \mathrm{~h}$ later. However, preliminary findings do show stability over $24 \mathrm{~h}$ and (short-term) effects on behavior have been reported. One could argue that these effects are unlikely to be sustained over longer periods of time, and may, therefore, have little relevance to prevention. However, one could also argue that if a relatively small experimental manipulation can result in changed behavior in the short term, the experience of the changed behavior could further affect the (global) implicit cognitions, which in turn may help to further change substance use patterns. This bears resemblance to recent research on automatizing desirable behavior (Gollwitzer, 1999), which can be used to develop strategies that make implicit cognitions work in favor of a desired change in behavior rather than against it. Obviously these speculations require empirical testing.

Finally, another possibility could be that the implicit substancerelated cognitions themselves are not changed through an intervention, but that the intervention strengthens the moderating effect of explicit cognitions or of more general executive control functions on the relation between implicit cognitions and behavior (here substance misuse) (see also Kahneman, 2003; Stacy et al., in this issue; Strack and Deutsch, 2004).

In conclusion, almost nothing is known about the application of implicit cognition concepts to drug use and misuse prevention as a specific arena of inquiry. The same can be said, from yet another perspective, about nonuse or abstinent behavior and lifestyles as well as temperate use. Certainly, TD collaboration, among researchers from learning, and cognitive science arenas is needed as well as the involvement of those who can translate basic research concepts into potential drug use and misuse prevention change ideas, and those who can translate ideas for new drug-use prevention efforts into concrete activities for application. There is growing evidence that implicit and explicit cognitions differentially affect substance use and misuse, and preliminary evidence that interventions may have differential effects on implicit and explicit cognitions. This should have implications for future transdisciplinary research on the prevention of substance use and misuse. Clearly, if one does not study implicit cognition, these differential effects cannot be found. In summary, these are interesting times to study implicit and explicit cognitions and the ways to change them, with promising findings in a variety of domains. Without wanting to go as far as Burgess' Dr. Brodsky and proposing enforced counterconditioning 
for substance misusers, we do believe that the recent developments in the area of implicit cognitions, have great potential for further prevention research and indeed can be described as: "Promising, promising."

\section{GLOSSARY}

Appetitive response: A motivational response generated by primary reinforcers (e.g., food, sex) that generates approach behavior (e.g., Franken, 2003).

Attentional bias in psychopathology: Stimuli relating to psychopathology (e.g., spider pictures for spider phobics or stimuli relating to alcohol for alcohol misusers) grab more attention than other stimuli. This can be due to a tendency to capture attention in an early stage of processing and/or due to a disengagement problem in a later stage of processing (e.g., Mogg et al., 2003).

Attentional retraining: This recently developed method aims to change an attentional bias related to psychopathology by training people to automatically direct their attention away from stimuli related to psychopathology, rather than to these stimuli (e.g., MacLeod et al., 2002).

Automatizing: With repetition (complex) behaviors can be automatized (e.g., driving a car), and this knowledge can be used in a prevention context (Bargh, 1999).

Context cues: More or less stable background stimuli, such as environmental context, or mood state.

Counter-conditioning: A Pavlovian conditioning procedure aimed at countering, or eliminating, an initially conditioned response by pairing the conditioned stimulus with another unconditioned stimulus. This procedure leads to the conditioning of a new response replacing the former response.

Craving: An affective-motivational state, generally expressed as a strong desire to use drugs.

Expectancy challenge: An experimental procedure that aims to reduce participants' positive expectancies of alcohol, and by doing so to reduce their level of substance misuse. In a group procedure, in which participants drink an alcoholic drink or a placebo drink, they learn that it is hard to judge who actually drank alcohol and this knowledge is used to indicate that many of their positive expectancies may be misguided (Darkes and Goldman, 1993). 
Explicit cognitive processes: Explicit cognitive processes are relatively controlled, slow conscious processes that require working memory (e.g., Greenwald and Banaji, 1995; Kahneman, 2003; Rudman, 2004; Strack and Deutsch, 2004; Wilson, 2002; Wilson et al., 2000).

Explicit measures: Explicit or direct measures require conscious access to memories and thoughts (e.g., a paper and pencil measure asking you what your general attitude is toward alcohol) (Fazio and Olson, 2003; Greenwald and Banaji, 1995).

Implicit cognitive processes: Implicit cognitive processes are relatively uncontrolled fast processes relying on associative memories (e.g., Greenwald and Banaji; 1995; Kahneman, 2003; Rudman, 2004; Strack and Deutsch, 2004; Wilson, 2002; Wilson et al., 2000).

Implicit measures: Implicit or indirect measures require little attention or conscious thoughts about what is being measured (e.g., a fast reaction to one or the other side). The implicit cognitions are indirectly derived, usually by comparing reaction times between conditions (see Appendix for examples) (Fazio and Olson, 2003; Greenwald and Banaji, 1995).

Incentive Sensitization Theory of Addiction: Robinson and Berridge $(1993,2001,2003)$ theorize that when psychoactive substances are misused, the initial psychomotor stimulant reaction sensitizes (becomes stronger) and this dopamine-mediated incentive salience response to drug cues is related to wanting, rather than to liking. In the case of addiction these processes that normally go together i.e., dissociate: addiction comes with compulsive wanting, even when the individual does not like his or her addiction anymore (which is not unlikely to happen, given the many negative consequences associated with addiction).

Motivational Interviewing: An empathic therapeutic technique aimed at building motivation to change undesirable behaviors (Dimeff et al., 1999).

Reinstatement: The return of a previously extinguished conditioned response after a single presentation of the unconditioned stimulus within the extinction context.

Renewal: The return of a previously extinguished conditioned response when the conditioned stimulus is presented outside the extinction context.

Unlearning: A term referring to the erroneous view that extinction of conditioned responding entails the gradual erasure of the association between the conditioned and unconditioned stimulus. 


\section{APPENDIX}

\section{Brief Description of the Tests Mentioned}

\section{Implicit Memory}

Repetition Priming (perceptual) (Roediger, 1990)

A stimulus is presented (primed). On a later test trial a brief presentation form or a degraded form is used. When the stimulus is completed more often with the primed word than without priming, this is evidence for an implicit memory effect.

Repetition Priming (semantic) (Roediger, 1990)

A rare exemplar of a category is primed. When in the test phase this rare exemplar occurs above baseline frequency, this is evidence for an implicit memory effect.

False Fame Paradigm (Jacoby and Kelly, 1987)

A list of names of nonfamous people is shown. Next, a new list of names, including some of the names from the first list, is presented. When these previously seen nonfamous people are more often rated as famous than are new nonfamous people, this is evidence for an implicit memory effect.

False Memory Paradigm (Roediger and McDermott, 1995)

Lists of words (bed, dream, tired etc.) pertaining to a semantically related word (sleep) are presented. There is evidence for false memory when these nonpresented target words are recalled or recognized.

\section{Attentional or Processing Bias}

Dot-Probe Task (MacLeod et al., 1986)

Two words are presented on different places on the computer screen (usually above and under a fixation spot). After this, a dot appears on 
one of the two places. The participant's task is to press as fast as possible the button corresponding with one of the two locations. An attentional or processing bias is evident when participants are faster in detecting the dot on the location where an emotionally relevant stimulus was presented just before the occurrence of the dot (e.g. a threat-related word in anxious people or a drug-related word in drug misusers).

Emotional Stroop (overview Williams et al., 1996)

Participant's task is to name the colors of words on the screen (nowadays most people use a computerized version of the Stroop, but the classical Stroop effect was obtained with cards with multiple stimuli). The classical Stroop effect concerns the slowing down of reaction times when the color of the word conflicts with the meaning of the word (e.g., the word "green" printed in blue). In the emotional Stroop, it is investigated whether participants are slower to name words that are emotionally relevant to them (e.g., name the color of the word death in a depressed person, or beer in an alcohol-dependent patient).

\section{Tests of Implicit Associations}

IAT (Implicit Association Test) (Greenwald et al., 1998)

Participants categorize stimuli that are presented one by one into one of four categories, two target categories (e.g., Sodas and Alcoholic Drinks) and two attribute categories (usually positive vs. negative; but other categories may be used as well). In the critical combination phases, stimuli from all four categories are mapped onto two response buttons in two different combinations. The IAT-effect is the difference in reaction times between the responses given in the one combination of target and attribute (e.g., alcohol with positive and soda with negative) and the reaction time give in the other combination (alcohol-negative and sodapositive). This frequently used measure gives a relative or bipolar index of the strength of the associations between targets and concepts (in the example, faster responses in the second phase could be due to stronger alcohol-negative associations than alcohol-positive associations and/or due to stronger soda-positive associations than soda-negative associations) (see De Houwer, 2001; Wiers and De Jong, in press; Wiers et al., 2002). 
GNAT (Go/No-go Association Task)

(Nosek and Banaji, 2001)

This variety of the IAT assesses the association strength between a target and attribute concept in a unipolar way. As in the IAT, participants react to stimuli that are presented one by one, but now there is only one response button. In a certain phase of the test, the participant is instructed to react as fast as possible to two categories and to ignore the other stimuli (distractors). Outcome measure is defined in terms of signal detection measures: the sensitivity to one target category (e.g., smoking) coupled with one attribute category (e.g., positive) is compared with the sensitivity to this target category as coupled with another attribute category (e.g., negative).

EAST (Extrinsic Affective Simon Task) (De Houwer, 2003)

The IAT as well as the GNAT provide measures of association strength that are influenced by the category label (e.g., alcohol) as well as by the specific exemplars (e.g. beer) (De Houwer, 2001; Mitchell et al., 2003). In the EAST, no category label is used, which makes it possible to obtain a purer measure of the association strength of specific exemplars. As in the IAT, stimuli are presented one by one and there are two response buttons. Participants first learn to categorize stimuli presented in the white font with respect to valence, which results in a positive or negative response button. Target stimuli (e.g., alcoholic drinks or sodas) have to be classified with respect to another irrelevant stimulus feature (e.g., color or the word). The color of the word determines which response button has to be used (the positive or the negative) button. In this way, one can compare whether a specific target (e.g., beer) is more easily processed to the positive side (e.g., in green font) or to the negative side (e.g., blue font), without a category label (alcohol). Typically on the EAST the effects are larger in the errors than in the reaction times (for the IAT the opposite is found). Note that in the EAST, the targets are assessed in a unipolar fashion (implicit attitudes for alcoholic drinks and sodas separately), but that the attribute dimension is bipolar.

Primed Stroop (e.g., Stewart et al., 2002)

Unlike the emotional and standard Stroop tests, the primed Stroop is used to assess associations between semantic categories. The target words 
have to be named by font-color (e.g., alcohol words vs. neutral words) and they are preceded by primes (e.g., positive and negative affect words or neutral words). In this way, response time (and errors) can be compared for the different categories of targets, in relation to the different primes (e.g., slower color naming of alcohol after a negative prime in coping drinkers; note that unlike the association tests presented above in the primed Stroop a slower reaction time indicates a stronger association, or more interference with color-naming).

Affective Priming (Fazio et al., 1986; Fazio, 2001)

A target word is preceded by a prime with a positive or negative valence (or a neutral prime). The rationale of the test is that it takes less time to respond to the target (with a lexical decision or naming or another task) when a prime of the same valence precedes it. The difference in response time for a target word with respect to primes of different valence categories provides a measure of the automatic attitude.

Semantic Priming (e.g., Zack et al., 1999)

Essentially the same as affective priming, but now the prime is from another semantic category (not necessarily valence). For example, the prime can be an alcoholic drink and the target either an alcoholic drink or a negative word or a neutral category (to test the alcohol $\rightarrow$ negative association) or the prime can be a negative word followed by a target that is an alcoholic drink or a negative word or a neutral association (to test the negative $>$ alcohol association). Note that unlike the IAT, EAST, and GNAT this method allows for the testing of unidirectional associations.

\section{ACKNOWLEDGMENT}

Reinout W. Wiers is supported by N.W.O. grant 452.02 .005 (VidiVernieuwingsimpuls). The authors wish to thank Susan Ames, Pepijn van Empelen, Herco Fonteijn, Ingmar Franken, Jan de Houwer, Anne Roefs, Alan Stacy, and Steve Sussman for comments and Marten van de Braak for assistance in manuscript preparation. 


\section{THE AUTHORS}
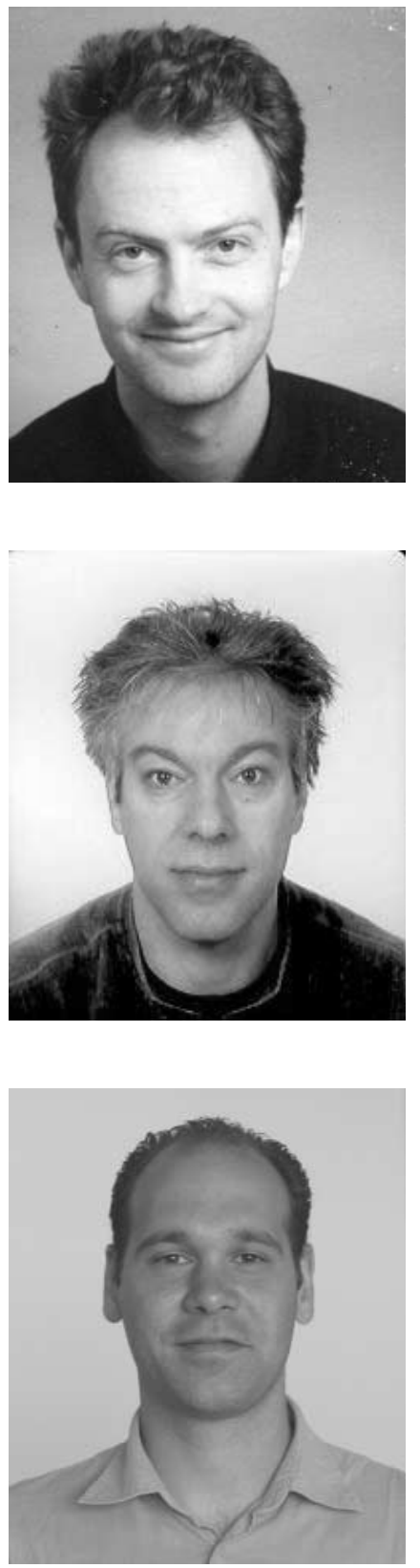

Reinout W. Wiers, Ph.D., is associate professor in the Department of Experimental Psychology at the University of Maastricht in The Netherlands. His research interests include implicit cognition, cognitive and biological aspects of addiction, and the prevention and treatment of substance use and misuse. He received his doctorate in 1998 from the University of Amsterdam.

Peter J. de Jong, Ph.D., is professor of Experimental Psychopathology in the Department of Clinical and Developmental Psychology at the University of Groningen, The Netherlands. His research interests include the role of information processing biases in the development and maintenance of clinical problems. $\mathrm{He}$ received his doctorate from the University of Maastricht, The Netherlands, in 1994.

Remco Havermans, M.Sc., is finishing his Ph.D., in the Department of Experimental Psychology at the University of Maastricht in The Netherlands. His research interests involve the associative nature of human learning and behavior, and more specifically the role of associative learning in the development, maintenance and relapse of addictive behaviors. 


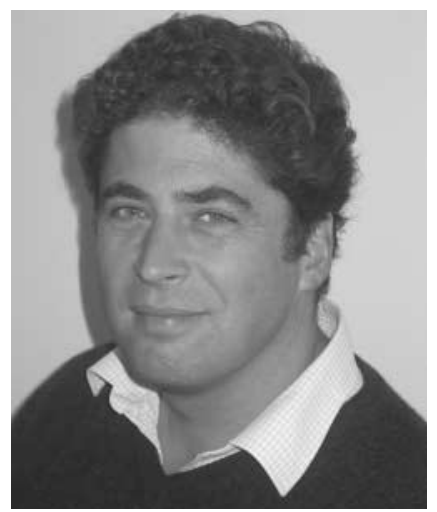

Marko Jelicic, Ph.D., is associate professor in the Department of Experimental Psychology at the University of Maastricht in The Netherlands. He is interested in basic and applied memory research, including work on implicit memory. He has published over 20 papers on implicit memory and coedited a book on the taxonomy of memory. He received his doctorate in psychology from Erasmus University, Rotterdam, The Netherlands, in 1992.

\section{REFERENCES}

Ashburne-Nardo, L., Voils, C. I., Monteith, M. J. (2001). J. Pers. Soc. Psychol. 81(5):789-799.

Baeyens, F., Eelen, P., Crombez, G. (1995). Pavlovian associations are forever: on classical conditioning and extinction. J. Psychophysiol. 9:127-141.

Baker, T. B., Morse, E., Sherman, J. E. (1987). The motivation to use drugs: a psychobiological analysis of urges. In: Rivers, C., ed. The Nebraska Symposium on Motivation: Alcohol Use and Abuse. Lincoln: University of Nebraska Press, 257-323.

Bargh, J. A., Chartrand, T. L. (1999). The unbearable automaticity of being. Am. Psychol. 54(7):462-479.

Barsalou, L. W. (1999). Perceptual symbol systems. Behav. Brain. Sci. 22(4):577-660.

Barsalou, L. W., Simmons, W. K., Barbey, A. K., Wilson, C. D. (2003). Grounding conceptual knowledge in modality-specific systems. Trends Cogn. Sci. 7(2):84-91.

Bechara, A., Damasio, H., Damasio, A. R. (2000). Emotion, decision making and the orbitofrontal cortex. Cereb Cortex 10:295-307.

Beck, A. T., Emery, G., Greenberg, R. L. (1985). Anxiety Disorders and Phobias: A Cognitive Perspective. New York: Basic Books.

Beck, A. T., Wright, F. D., Newman, C. F., Liese, B. S. (1993). Cognitive Therapy of Substance Abuse. New York/London: The Guilford Press.

Blair, I. V. (2002). The malleability of automatic stereotypes and prejudice. Pers. Soc. Psychol. Rev. 6(3):242-261. 
Blair, I. V., Ma, J. E., Lenton, A. P. (2001). Imaging stereotypes away: the moderation of implicit stereotypes through mental imagery. J. Pers. Soc. Psychol 81(5):828-841.

Bosson, J. K., Swann, W. B., Pennebaker, J. (2000). Stalking the perfect measures of implicit self-esteem: the blind man and the elephant revisited? J. Pers. Soc. Psychol. 79:631-643.

Bouton, M. E. (1993). Context, time and memory retrieval in the interference paradigms of pavlovian learning. Psychol. Bull. 114:80-99.

Bradley, M. M. (2000). Emotion and motivation. In: Cacioppo, J. T., Tassinary, L. G., Berntson, G. G., eds. Handbook of Psychophysiology. 2nd ed. New York: Cambridge University Press, 602-642.

Bradley, B. P., Mogg, K., Wright, T., Field, M. (2003). Attentional bias in drug dependence: vigilance for cigarette-related cues in smokers. Psychol. Addict. Behav. 17(1):66-72.

Brooks, D. C., Karamanlian, B. R., Foster, V. (2001). Extinction and spontaneous recovery of ataxic tolerance to ethanol in rats. Psychopharmacology 153:491-496.

Burgess, A. (1962). A Clockwork Orange. London: Penguin.

Chassin, L., Presson, C., Rose, J., Sherman, S. J., Prost, J. (2002). Parental smoking cessation and adolescent smoking. J. Pediatr. Psychol. 27:485-496.

Collins, B. N., Brandon, T. H. (2002). Effects of extinction context and retrieval cues on alcohol cue reactivity among nonalcoholic drinkers. J. Consult. Clin. Psychol. 70:390-397.

Conklin, C. A., Tiffany, S. T. (2002). Applying extinction research and theory to cue-exposure addiction treatments. Addiction 97:155-167.

Cooper, M. L., Frone, M. R., Russell, M., Mudar, P. (1995). Drinking to regulate positive and negative emotions: a motivational model of alcohol use. J. Pers. Soc. Psychol. 69:990-1005.

Cox, W. M., Klinger, E. (1988). A motivational model for alcohol use. J. Abnorm. Psychol. 97:168-180.

Cox, W. M., Hogan, L. M., Kristian, M. R., Race, J. H. (2002). Alcohol attentional bias as predictor of alcohol abusers' treatment outcome. Drug alcohol depend 68:237-243.

Crombag, H. S., Shaham, Y. (2002). Renewal of drug seeking by contextual cues after prolonged extinction in rats. Behav. Neurosci. 116:169-173.

Cunningham, W. A., Preacher, K. J., Banaji, M. R. (2001). Implicit attitude measures: consistency, stability and convergent validity. Psychol. Sci. 12:163-170. 
Damasio, A. (1999). The feeling of what happens. Body and Emotion in the Making of Consciousness. NY: Harcourt.

Dandeneau, S. T., Baldwin, M. W. (2004). The inhibition of socially rejecting information among people with high versus low selfesteem: The role of attentional bias and the effects of bias reduction training. J. Soc. Clin. Psychol. 23:584-602.

Darkes, J., Goldman, M. S. (1993). Expectancy challenge and drinking reduction: experimental evidence for a mediational process. J. Consult Clin. Psychol. 61:344-353.

Darkes, J., Goldman, M. S. (1998). Expectancy challenge and drinking reduction: process and structure in the alcohol expectancy network. Exp. Clin. Psychopharmacol. 6:64-76.

Dasgupta, N., Greenwald, A. G. (2001). On the malleability of automatic attitudes: combating automatic prejudice with images of admired and disliked individuals. J. Pers. Soc. Psychol. 81(5):800-814.

De Houwer, J. (2001). A structural and process analysis of the implicit association test. J. Exp. Soc. Psychol. 37:443-451.

De Houwer, J. (2003). The extrinsic affective simon task. Exp. Psychol. 50:77-85.

De Houwer, J., Crombez, G., Koster, E.H.W., De Beul, N. (2003). Implicit alcohol-related cognitions in a clinical sample of heavy drinkers. Unpublished manuscript.

De Houwer, J., Thomas, S., Baeyens, F. (2001). Associative learning of likes and dislikes: a review of 25 years of research on human evaluative conditioning. Psychol. Bull. 127:853-869.

De Jong, P. J., Van den Hout, M. A., Rietbroek, H., Huijding, J. (2003). Dissociations between implicit and explicit attitudes towards phobic stimuli. Cogn. Emotion 17:521-545.

Dijksterhuis, A. (2004). I like myself but i don't know why: enhancing implicit self-esteem by subliminal evaluative conditioning. J. Pers. Soc. Psychol. 86:345-355.

Dijkstra, A., De Vries, H., Roijackers, J. M. A. (1999). Targeting smokers with low readiness to change with tailored and nontailored self-help materials. Prev. Med. 28:203-211.

Dimeff, L. A., Baer, J. S., Kivlahan, D. R., Marlatt, G. A. (1999). Brief Alcohol Screening and Intervention for College Students (BASICS): A Harm Reduction Aapproach. New York,: The Guilford Press.

Dishion, T. J., McCord, J., Poulin, F. (1999). When interventions harm. Peer groups and problem behavior. Am. Psychol. 54:755-764.

Dovidio, J. F., Kawakami, K., Beach, K. R. (2001). Implicit and explicit attitudes: Examination of the relations between measures of intergroup bias. In: Brown, R., Gaertner, S., eds. Blackwell 
Handbook of Social Psychology: Intergroup Processes. Oxford: Blackwell Publishing, 175-197.

Edelman, G. M. (1990). The Remembered Present: A Biological Theory of Consiousness. NY: Basic Books.

Ehlers, A., Margraf, J., Davies, S., Roth, W. T. (1988). Selective processing of threat cues in subjects with panick attacks. Cogn. Emotion 2:201-220.

Erblich, J., Earleywine, M., Erblich, B. (2001). Positive and negative associations with alcohol and familial risk for alcoholism. Psychol. Addict. Behav. 15:204-209.

Fazio, R. H. (1990). Multiple processes by which attitudes guide behavior: the MODE model as an integrative framework. In: Zanna, M. P., ed. Advances in Experimental Social Psychology. San Diego, CA: Academic Press, 23:75-109.

Fazio, R. H. (2001). On the automatic activation of associated evaluations: an overview. Cogn. Emotion 15:115-141.

Fazio, R. H., Jackson, J. R., Dunton, B. C., Williams, C. J. (1995). Variability in automatic activation as an unobtrusive measure of racial attitudes. a bona fide pipeline? J. Pers. Soc. Psychol. 69:1013-1027.

Fazio, R. H., Olson, M. A. (2003). Implicit measures in social cognition research: their meaning and use. Annu. Rev. Psychol. 54:297-327.

Fazio, R. H., Sanbonmatsu, D. M., Powell, M. C., Kardes, F. R. (1986). On the automatic activation of attitudes. J. Pers. Soc. Psychol. 50:229-238.

Fox, E., Russo, R., Bowles, R., Dutton, K. (2001). Do threatening stimuli draw or hold visual attention in subclinical anxiety? J. Exp. Psychol. 681-700.

Franken, I. H. A. (2003). Drug craving and addiction: Integrating psychological and neuropsychopharmacological approaches. Prog. Neuropsychopharmacol. Biol. Psychiatry 27:563-579.

Franken, I. H. A., Hendriks, V. M., Stam, C. J., Van den Brink, W. (2004). Haloperidol improves biased cognitive processing of drug cues in heroin dependence. Neuropsychopharmacol.

Franken, I. H. A., Kroon, L. Y., Wiers, R. W., Jansen, A. (2000). Selective processing of drug cues in heroin dependence. $J$. Psychopharmacol. 14:395-400.

Franken, I. H. A., Rosso, M. M., Van Honk, J. (2003). Selective memory for alcohol cues in alcoholics and its relation to craving. Cognitive Therapy and Research 27:481-488.

Gabrieli, J. D. E. (1999). The architecture of human memory. In: Foster, J. K., Jelicic, M., eds. In Memory: Systems, Process or Function?. Oxford: Oxford University Press, 205-231. 
García-Gutiérrez, A., Rosas, J. M. (2003). Empirical and theoretical implications of additivity between reinstatement and renewal after interference in causal learning. Behav. Processes 63:21-31.

Gerald, M. S., Higley, J. D. (2002). Evolutionary underpinnings of excessive alcohol consumption. Addiction 97:415-425.

Glautier, S., Remington, B. (1995). The form of responses to drug cues. In: Drummond, D. C., Tiffany, S. T., Glautier, S., Remington, B., eds. Addictive Behaviour: Cue Exposure Theory and Practice. Chichester: John Wiley \& Sons, 21-46.

Goldman, M. S. (1999). Risk for substance abuse: memory as final common pathway. Psychol. Sci. 10:196-198.

Goldman, M. S., Brown, S. A., Christiansen, B. A. (1987). Expectancy theory: thinking about drinking. In: Blane, H. T., Leonard, K. E., eds. Psychological theories of drinking and alcoholism. New York: Guilford, 181-226.

Goldman, M. S., Darkes, J., DelBoca, F. K. (1999). Expectancy mediation of biopsychosocial risk for alcohol use and addiction. In: Kirsch, I., ed. Expectancy, Experience, and Behavior. Washington: APA Books, 233-262.

Goldman, M. S., Del Boca, F. K., Darkes, J. (1999). Alcohol expectancy theory: the application of cognitive neuroscience. In: Blane, H. T., Leonard, K. E., eds. Psychological Theories of Drinking and Alcoholism. 2nd ed. The Guilford Substance Abuse Series, New York, NY, USA: The Guilford Press, 203-246.

Gollwitzer, P. M. (1999). Implementation intentions: strong effects of simple plans. Am. Psychol. 54:493-503.

Graf, P., Mandler, G. (1984). Activation makes words more accessible, but not necessarily more retrievable. Journal of Verbal Learning and Verbal Behavior 23:553-568.

Graf, P., Shimamura, A. P., Squire, L. R. (1985). Priming across modalities and across category levels: Extending the domain of preserved function in amnesia. J. Exp. Psychol: Learn Mem. Cogn. 11:386-396.

Greenwald, A. G., Banaji, M. R. (1995). Implicit social cognition: attitudes self-esteem, and stereotypes. Psychol. Rev. 102(1):4-27.

Greenwald, A. G., McGhee, D. E., Schwartz, J. L. K. (1998). Measuring individual differences in implicit cognition: the implicit association test. J. Pers. Soc. Psychol. 74(6):1464-1480.

Greenwald, A. G., Nosek, B. A., Banaji, M. R. (2003). Understanding and using the implicit association test: 1. an improved scoring algorithm. J. Pers. Soc. Psychol. 85:197-216. 
Havermans, R. C., Jansen, A. T. M. (2003). Increasing the efficacy of cue exposure treatment in preventing relapse of addictive behavior. Addict. Behav. 28:989-994.

Hebb, D. O. (1946). Emotion in man and animal: an analysis of the intuitive processes of recognition. Psychol. Rev. 53:88-106.

Hirshman, E., Passannante, A., Arndt, A. (2001). Midazolam amnesia and conceptual processing in implicit memory. J. Exp. Psychol. Gen. 130:453-465.

Hope, D. A., Rapee, R. M., Heimberg, R. G., Dombeck, M. J. (1990). Representations of the self in social phobia: vulnerability to social threat. Cognitive Therapy and Research 14:177-189.

Huijding, J., De Jong, P. J., Wiers, R. W., Verkooijen, K. (submitted for publication). Implicit attitudes toward smoking in a smoking and non-smoking setting.

Jacoby, L. L., Dallas, M. (1981). On the relationship between autobiographical memory and perceptual learning. J. Exp. Psychol. Gen. 110:306-340.

Jacoby, L. L., Kelley, C. M. (1987). Unconscious influences of memory for a prior event. Pers. Soc. Psychol. Bull. 13:314-336.

Jacoby, L. L., Kelley, C. M., Brown, J., Jasechko, J. (1989). Becoming famous overnight: limits on the ability to avoid unconscious influences of the past. J. Pers. Soc. Psychol. 56(3):326-338.

Jajodia, A., Earleywine, M. (2003). Measuring alcohol expectancies with the implicit association test. Psychol. Addict. Behav. 17(2):126-133.

Jelicic, M., Craik, F. I. M., Moscovitch, M. (1996). Effects of ageing on different explicit and implicit memory tasks. Eur. J. Cogn. Psychol. 8:225-235.

Jones, B. T., McMahon, J. (1998). Alcohol motivations as outcome expectancies. In: Miller, W. R., Heather, N., eds. Treating Addictive Behaviors Applied Clinical Psychology. 2nd ed. New York: Plenum Press, 75-91.

Jones, B. T., Corbin, W., Fromme, K. (2001). A review of expectancy theory and alcohol consumption. Addiction 91:57-72.

Kahneman, D. (2003). A perspective on judgment and choice. Mapping bounded rationality. American Psychologist 58:697-720.

Kawakami, K., Dovidio, J. F., Moll, J., Hermsen, S., Russin, A. (2000). Just say no (to stereotyping): effects of training in the negation of stereotopic associations on stereotype activation. J. Pers. Soc. Psychol. 78(5):871-888.

Krank, M. D., Kreklewetz, K. L. (2003). Exposure to alcohol advertising increases implicit alcohol cognitions in adolescents. In: Poster 
Presented at the Annual Meeting of the Research Society on Alcoholism (RSA). Fort Lauderdale, FL, June 21-25.

Krank, M. D., Swift, R. (1994). Unconscious influences of specific memories on alcohol outcome expectancies. Alcohol Clin. Exp. Res. 18:423.

Kraus, D., Smith, G. T., Ratner, H. H. (1994). Modifying alcohol-related expectancies in grade-school children. J. Stud. Alcohol. 55:535-542.

Lavy, E. H., Van den Hout, M. A. (1993). Selective attention evidenced by pictorial and linguistic Stroop tasks. Behav. Ther. 24:645-657.

Lavy, E. H., Van den Hout, M. A., Arntz, A. (1993). Attentional bias and spider phobia: conceptual and clinical issues. Behav. Res. Ther. 31:17-24.

Lovibond, P. F., Shanks, D. R. (2002). The role of awareness in pavlovian conditioning: empirical evidence and theoretical implications. J. Exp. Psychol. Anim. Behav. Process. 25:211-224.

MacLeod, C., Hagan, R. (1992). Individual differences in the selective processing of threatening information, and emotional responses to a stressful life event. Behav. Res. Ther. 30:151-161.

MacLeod, C., Matthews, A., Tata, P. (1986). Attentional bias in emotional disorders. J. Abnormal. Psychol. 95:15-20.

MacLeod, C., Rutherford, E., Campbell, L., Ebsworthy, C., Holker, L. (2002). Selective attention and emotional vulnerability: assessing the causal basis of their association through the experimental manipulation of attentional bias. J. Abnorm. Psychol. 111:107-123.

Maio, G. R., Watt, S. E. (submitted for publication). Effects of anti-racism messages on explicit and implicit intergroup attitudes: the moderating role of attitudinal ambivalence.

Mansell, W. (2000). Conscious appraisal and the modification of automatic processes in anxiety. Behav. Cogn. Psychother 28:99-120.

Marlatt, G. A., Baer, J. S., Kivlahan, D. R., Dimeff, L. A., Larimer, M. E., Quigley, L. A., Somers, J. M., Williams, E. (1998). Screening and brief intervention for high-risk college student drinkers: results from a 2-year follow-up assessment. J. Consult. Clin. Psychol. 66:604-615.

Mathews, A., MacLeod, C. (2002). Induced processing biases have causal effects on anxiety. Cogn. Emot. 16(3):331-354.

Mathews, A., Mogg, K., Kentish, J., Eysenck, M. (1995). Effect of psychological treatment on cognitive bias in generalized anxiety disorder. Behav. Res. Ther. 33:293-303.

Mattia, J. I., Heimberg, R. G., Hope, D. A. (1993). The revised Stroop color-naming task in social phobics. Behav. Res. Ther. 31:305-313. 
McClelland, J. L., Rummelhart, D. E. (1985). Distributed memory and the representation of general and specific information. J. Exp. Psychol. Gen. 114:159-188.

McGue, M. (1999). Behavioral genetic models of alcoholism and drinking. In: Blane, H. T., Leonard, K. E., eds. Psychological Theories of Drinking and Alcoholism. 2nd ed. The Guilford Substance Abuse Series, New York, NY: The Guilford Press, 372-421.

McNally, R. J. (1995). Automaticity and the anxiety disorders. Behav. Res. Ther. 33:747-754.

Meiran, N., Jelicic, M. (1995). Implicit memory in Alzheimer's disease: a meta-analysis. Neuropsychology 9:291-303.

Merckelbach, H., Van Hout, W., De Jong, P. J., Van den Hout, M. A. (1990). Classical conditioning and attentional bias. J. Behav. Ther. Exp. Psychiatry 21:185-191.

Merikle, P. M., Smilek, D., Eastwood, J. D. (2001). Perception without awareness: perspectives from cognitive psychology. $\operatorname{Cog} n$. 79:115-134.

Miller, W. R., Rollnick, G. A. (2002). Motivational Interviewing: Preparing People to ChangeAddictive Behavior. 2nd ed. New York: Guilford Press.

Mitchell, J. P., Nosek, B. A., Banaji, M. R. (2003). Contextual variations in implicit evaluation. J. Exp. Psychol. Gen. 132:455-469.

Mogg, K., Bradley, B. P., Field, M., De Houwer, J. (2003). Eye movements to smoking-related pictures in smokers: relationship between attentional biases and implicit and explicit measures of stimulus valence. Addiction 98:825-836.

Mogg, K., Bradley, B. P., Millar, N., White, J. (1995). A follow-up study of cognitive bias in generalized anxiety disorder. Behav. Res. Ther. 33:927-935.

Mucha, R. F., Geier, A., Pauli, P. (1999). Modulation of craving by cues having differential overlap with pharmacological effect: evidence for cue approach in smokers and "social drinkers." Psychopharmacology 147:306-313.

Mulligan, N. W., Stone, M. (1999). Attention and conceptual priming: limits on the effects of divided attention in the category-exemplar production task. J. Mem. Lang. 41:253-280.

Mulligan, N. W., Guyer, P. S., Beland, A. (1999). The effects of levelsof-processing and organization on conceptual implicit memory in the category exemplar production test. Mem. Cognit. 27:633-647.

Nelson, J. B. (2002). Context specificity of excitation and inhibition in ambiguous stimuli. Learn. motiv. 33:284-310.

Nisbett, R. E., Wilson, T. D. (1977). Telling more than we can know: verbal reports on mental processes. Psychol. Rev. 84:231-259. 
Nosek, B. A., Banaji, M. R. (2001). The Go/No-Go association task. Soc. Cogn. 19:625-664.

Olson, M. A., Fazio, R. H. (2001). Implicit attitude formation through classical conditioning. Psychol. Sci. 12(5):413-417.

Olson, M. A., Fazio, R. H. (2003). Relations between implicit measures of prejudice: what are we measuring? Psychol. Sci. 14:636-639.

Palfai, T. P., Ostafin, B. D. (2003). Alcohol-related motivational tendencies in hazardous drinkers: assessing implicit response tendencies using the modified IAT. Behav. Res. Ther. 41:1149-1162.

Parkin, A. J. (1993). Memory: Phenomena, Experiment and Theory. Oxford: Blackwell.

Parkin, A. J., Russo, R. (1990). Implicit and explicit memory and the automatic/effortful distinction. Eur. J. Cogn. Psychol. 2:71-80.

Pearce, J. M., Bouton, M. E. (2001). Theories of associative learning in animals. Annu. Rev. Psychol. 52:111-139.

Penfield, W., Welch, K. (1951). The supplementary motor cortex of the cerebral cortex. Arch. Neurol. Psychiat. 66:289-317.

Pihl, R. O., Bruce, K. R. (1995). Cognitive impairments in children of alcoholics. Alcohol Health Res. World 19:142-147.

Reingold, E. M., Toth, J. P. (1996). Process dissociations versus task dissociations: a controversy in progress. In: Underwood, G., ed. In Implicit Cognition. Oxford, UK: Oxford University Press, 159-202.

Rescorla, R. A. (1988). Pavlovian conditioning. It's not what you think it is. Am. Psychol. 43(3):151-160.

Rescorla, R. A. (2001). Experimental extinction. In: Mowrer, R. R., Klein, S. B., eds. Handbook of Contemporary Learning Theories. Mahwah, NJ: Lawrence Erlbaum Associates, 119-154.

Rescorla, R. A., Heth, C. D. (1975). Reinstatement of fear to an extinguished conditioned stimulus. J. Exp. Psychol. Anim. Behav. Process 1:88-96.

Robinson, T. E., Berridge, K. C. (1993). The neural basis of drug craving: an incentive-sensitization theory of addiction. Brain Res. Rev. 18:247-291.

Robinson, T. E., Berridge, K. C. (2001). Mechanisms of action of addictive stimuli. Incentive-sensitization and addiction. Addiction 96:103-114.

Robinson, T. E., Berridge, K. C. (2003). Addiction. Annu. Rev. Psychol. 54:25-53.

Roediger, H. L. (1990). Implicit memory: retention without remembering. Am. Psychol. 45:1043-1056. 
Roediger, H. L. (2003). Reconsidering implicit memory. In: Bowers, J. S., Marsolek, C. J., eds. Rethinking Implicit Memory. Oxford: Oxford University Press, 3-18.

Roediger III, H. L., McDermott, K. B. (1995). Creating false memories: remembering words not presented in lists. J. Exp. Psychol. Learn Mem. Cogn. 21:803-814.

Rohsenow, D. J., Monti, P. M., Abrams, D. B. (1995). Cue exposure treatment in alcohol dependence. In: Drummond, D. C., Tiffany, S. T., Glautier, S., Remington, B., eds. Addictive Behaviour: Cue Exposure Theory and Practice. Chichester: John Wiley \& Sons, 169-196.

Rudman, L. A. (2004). Sources of implicit attitudes. Curr. Dir. Psychol. Sci. 13:79-82.

Rudman, L. A., Ashmore, R. D., Gary, M. L. (2001). "Unlearning" automatic biases: the malleability of implicit prejudice and stereotypes. J. Pers. Soc. Psychol. 81(5):856-868.

Rudman, L. A., Heppen, J. B. (submitted for publication). Sources of Implicit attitudes toward smoking.

Schacter, D. L. (2001). The Seven Sins of Memory. New York: Houghton Mifflin.

Schwartz, N. (1999). Self-reports How questions shape the answers. Am. Psychol. 54:93-105.

Sher, K. J. (1991). Children of Alcoholics, a Critical Appraisal of Theory and Research. Chicago: University of Chicago Press.

Sherman, S. J., Presson, C. C., Chassin, L., Rose, J. S., Koch, K. (2003). Implicit and explicit attitudes toward cigarette smoking: the effects of context and motivation. J. Soc. Clin. Psychol. 22:13-39.

Spruyt, A., Hermans, D., De Houwer, J., Eelen, P. (2002). On the nature of the affective priming effect: affective priming of naming responses. Soc. Cogn. 227-256.

Squire, L. R. (1992). Memory and the hippocampus: a synthesis from findings with rats, monkeys, and humans. Psychol. Rev. 2:195-231.

Stacy, A. W. (1997). Memory activation and expectancy as prospective predictors of alcohol and marihuana use. J. Abnorm. Psychol. 106:61-73.

Stacy, A. W., Ames, S. L. (2001). Implicit cognition theory in drug use and driving under the influence interventions. In: Sussman, S., ed. Handbook of Program Development in Health Behavior Research and Practice. Thousand Oaks, CA: Sage Publications, 107-130.

Stacy, A. W., Ames, S. L., Knowlton, B. (2004). Neurologically plausible distinctions in cognition and habit relevant to drug abuse prevention. Subst. Use Misuse. 
Stewart, S. H., Hall, E., Wilkie, H., Birch, C. (2002). Affective priming of alcohol schema in coping and enhancement motivated drinkers. Cogn. Behav. Ther. 31:68-80.

Strack, F., Deutsch, R. (2004). Reflective and impulsive determinants of social behavior. Personal. Soc. Psychol. Rev. 3:220-247.

Swanson, J. E., Rudman, L. A., Greenwald, A. G. (2001). Using the implicit association test to investigate attitude-behavior consistency for stigmatized behavior. Cogn. Emot. 15:207-230.

Teachman, B. A., Woody, S. R. (2003). Automatic processing in spider phobia: implicit fear associations over the course of treatment. J. Abnorm. Psychol. 112:100-109.

Teachman, B. A., Gregg, A. P., Woody, S. R. (2001). Implicit associations for fear-relevant stimuli among individuals with snake and spider fears. J. Abnorm. Psychol. 110:226-235.

Tiffany, S. T. (1990). A cognitive model of drug urges and drug-use behavior: role of automatic and nonautomatic processes. Psychol. Rev. 97:147-168.

Tulving, E., Schacter, D. L., Stark, H. A. (1982). Priming effects in word fragment completion are independent of recognition memory. J. Exp. Psychol. Learn. Mem. Cogn. 8:336-342.

Vacey, M. W., Hazen, R., Schmidt, N. B. (2002). Attentional retraining for chronic worry and generalized anxiety disorder. In: Paper Presented at the 36th Annual Conference of the American Association of Behavior Therapy.

Van den Hout, M. A., Tenney, N., Huijgens, K., De Jong, P. J. (1997). Preconscious processing bias in specific phobia. Behav. Res. Ther. 35:29-34.

Waters, A., Shiffman, S., Bradley, B. P., Mogg, K. (2003). Attentional shifts to smoking cues in smokers. Addiction 98:1409-1417.

Waters, A. J., Shiffman, S., Sayette, M. A., Patty, J. A., Gwalney, C. J., Balabanis, M. H. (2003). Attentional bias predicts outcome in smoking cessation. Health Psychol. 22(4):378-387.

Watkins, P. C. (2002). Implicit memory bias in depression. Cogn. Emo. 16(3):381-402.

Wiers, R. W. (1992). The nature of natural representation. Memo 124, VF-Project Knowledge Acquisition in Formal Domains. University of Amsterdam, Faculty of Psychology, Amsterdam, The Netherlands.

Wiers, R. W., De Jong, P. J. (in press). Implicit and explicit alcohol, smoking and drug-related cognitions and emotions. In: Columbus, F., ed. Progress in Social Psychology. Hauppauge, NY: Nova Science Publishers. 
Wiers, R. W., Gunning, W. B., Sergeant, J. A. (1998). Do young children of alcoholics hold more positive or negative alcohol-related expectancies than controls? Alcohol. Clin. Exp. Res. 22:1855-1863.

Wiers, R. W., Gunning, W. B., Sergeant, J. A. (1998). Is a mild deficit in executive functions in boys related to childhood ADHD or to parental multigenerational alcoholism? J. Abnorm. Child Psychol. 26:415-430.

Wiers, R. W., Hartgers, C. A., Van den Brink, W., Gunning, W. B., Sergeant, J. A. (2000). A confirmatory analysis of the hierarchical structure of positive and negative dose-related alcohol expectancies in alcoholics and the associations with family history of alcoholism. J. Stud. Alc. 61:177-186.

Wiers, R. W., Sergeant, J. A., Gunning, W. B. (2000). The assessment of alcohol expectancies in school children: measurement or modification? Addiction 95:737-746.

Wiers, R. W., Van de Luitgaarden, J., Van den Wildenberg, E., Smulders, F. T. Y. (submitted for publication). Challenging implicit and explicit alcohol-related cognitions in young heavy drinkers.

Wiers, R. W., Van Woerden, N., Smulders, F. T. Y., De Jong, P. J. (2002). Implicit and explicit alcohol-related cognitions in heavy and light drinkers. J. Abnorm. Psychol. 111:648-658.

Wiers, R. W., Wood, M. D., Darkes, J., Corbin, W. R., Jones, B. T., Sher, K. J. (2003). Changing expectancies: cognitive mechanisms and context effects. Alcohol. Clin. Exp. Res. 27:186-197.

Williams, J. M. G., Mathews, A., MacLeod, C. (1996). The emotional Stroop task and psychopathology. Psychol. Bull. 120:3-24.

Wilson, T. D. (2002). Strangers to ourselves. Discovering the Adaptive Unconscious. Cambridge, MA: Belknap Press/Harvard University Press.

Wilson, T. D., Lindsey, S., Schooler, T. Y. (2000). A model of dual attitudes. Psychol. Rev. 107(1):101-126.

Wolters, G., Prinsen, A. (1997). A full versus divided attention and implicit memory performance. Mem. Cognit. 25:764-771.

Zack, M., Poulos, C. X., Fragopoulos, F., MacLeod, C. M. (2003). Effects of negative and positive mood phrases on priming of alcohol words in young drinkers with high and low anxiety sensitivity. Exp. Clin. Psychopharmacol. 11:176-185.

Zack, M., Toneatto, T., MacLeod, C. M. (1999). Clinical use of benzodiazepines and decreased memory activation in anxious problem drinkers. Alcohol. Clin. Exp. Res. 23:174-182.

Zack, M., Toneatto, T., MacLeod, C. M. (1999). Implicit activation of alcohol concepts by negative affective cues distinguishes between problem drinkers with high and low psychiatric distress. J. Abnorm. Psychol. 108:518-531. 


\section{Request Permission or Order Reprints Instantly!}

Interested in copying and sharing this article? In most cases, U.S. Copyright Law requires that you get permission from the article's rightsholder before using copyrighted content.

All information and materials found in this article, including but not limited to text, trademarks, patents, logos, graphics and images (the "Materials"), are the copyrighted works and other forms of intellectual property of Marcel Dekker, Inc., or its licensors. All rights not expressly granted are reserved.

Get permission to lawfully reproduce and distribute the Materials or order reprints quickly and painlessly. Simply click on the "Request Permission/ Order Reprints" link below and follow the instructions. Visit the U.S. Copyright Office for information on Fair Use limitations of U.S. copyright law. Please refer to The Association of American Publishers' (AAP) website for guidelines on Fair Use in the Classroom.

The Materials are for your personal use only and cannot be reformatted, reposted, resold or distributed by electronic means or otherwise without permission from Marcel Dekker, Inc. Marcel Dekker, Inc. grants you the limited right to display the Materials only on your personal computer or personal wireless device, and to copy and download single copies of such Materials provided that any copyright, trademark or other notice appearing on such Materials is also retained by, displayed, copied or downloaded as part of the Materials and is not removed or obscured, and provided you do not edit, modify, alter or enhance the Materials. Please refer to our Website User Agreement for more details.

\section{Request Permission/Order Reprints}

Reprints of this article can also be ordered at http://www.dekker.com/servlet/product/DOI/101081JA200033206 